\title{
Das Recht der Nachrichtendienste: Missstände, Entwicklungen und Perspektiven eines Rechtsgebiets in der Findungsphase*
}

\begin{abstract}
The law governing the German intelligence services lacks a consistent concept, is non-transparent, fragmented and in urgent need of reform. In May 2020, the First Senate of the Federal Constitutional Court held that the Federal Intelligence Service (Bundesnachrichtendienst - BND) is bound by the fundamental rights of the Basic Law when conducting telecommunications surveillance of foreigners in other countries (so-called Foreign-Foreign Strategic Surveillance), and that the statutory bases in their current design violate the fundamental right to the privacy of telecommunication and freedom of the press. The judgment put an end to the long-running discussion about whether intelligence operations abroad are suitable for statutory regulation at all. Moreover, the Constitutional Court's decision provided the impetus for one of the most significant reforms in recent German security law. By April 2021, the amendment of the BND Act was finally on the books. It will enter into force in January 2022. It codifies important new rules about the practice, authorization and oversight of foreign data collection by the BND as well as legal requirements for Germany's participation in international intelligence cooperation. The reform's provisions implement the constitutional requirements, as stated in the judgement, almost literally. Nonetheless, the reform created a number of new problems and left major deficits in German intelligence law unresolved. It is far from creating a clear and consistent legal framework for the activities of the three federal intelligence services, in particular their surveillance practices. The article outlines the major shortcomings, developments and perspectives in this field of security law.
\end{abstract}

\section{Résumé}

La loi allemande sur les services de renseignements manque un concept cohérent, elle est non-transparente, fragmentée et a grand besoin de réforme. En mai 2020, le premier sénat de la Cour constitutionnelle fédérale a décidé que le service de renseignements fédéral (Bundesnachrichtendienst - BND) doit respecter les droits fondamentaux de la Loi fondamentale lorsqu'il conduit la surveillance des télécommunications de personnes étrangères dans un autre pays et que les bases légales dans leur version actuelle violent le droit fondamental à la confidentialité de la télécommunication et de la liberté de la presse. La décision a mis un terme à la discussion conduite pendant longtemps sur la question de savoir si les activités de surveillance sont du tout susceptible à la régulation légale. De plus, la décision de la Cour constitutionnelle fédérale a donné l'impulsion pour une des réformes les plus importantes du droit de

* Prof. Dr. Tristan Barczak, LL.M. ist Inhaber des Lehrstuhls für Öffentliches Recht, Sicherheitsrecht und das Recht der neuen Technologien an der Universität Passau. Sämtliche Internetquellen wurden letztmalig abgerufen am 17.8.2021. 
sécurité allemand récent. Jusqu'en avril 2021 la modification de la loi sur le BND était finalement accomplie. Elle prendra effet en janvier 2022. Elle codifie des principes importants sur la pratique, l'autorisation et la surveillance de la collection des données étrangères de la part du BND ainsi que les exigences légales pour la participation de l'Allemagne à la coopération internationale des services de renseignements. Les dispositions de la réforme mettent en ouvre les exigences constitutionnelles précisées par la décision presque littéralement. Néanmoins, la réforme a créé de nouveaux problèmes et a laissé des déficits principaux $d u$ droit de sécurité allemand irrésolus. Elle est loin de créer un cadre légal précis et cohérent pour les activités des trois services de renseignements fédéraux, en particulier leurs pratiques de surveillance. L'article présente les déficits principaux, les développements et les perspectives de ce domaine juridique du droit de sécurité.

\section{A. Nachrichtendienstrecht: Zwischen nachholender Verrechtlichung und dogmatischer Konzeptionslosigkeit}

Wie kaum ein anderes Rechtsgebiet war und ist das Recht der Nachrichtendienste eine Disziplin, deren Gegenstand sich wesensgemäß im Undurchsichtigen, Klandestinen und Opaken entfaltet und die insoweit ungleich schwerer zugänglich ist als vergleichbare Teilbereiche des Rechts. ${ }^{1}$ Die Generierung von Herrschaftswissen im Verborgenen sowie im steten Verdacht der Grenzgängerschaft zwischen Legalität und Illegalität tangiert das innerste Arkanum staatlicher Machtentfaltung. ${ }^{2}$ Dies hat die öffentliche Wahrnehmung und den wissenschaftlichen Diskurs nicht unberührt gelassen: Eine Selbstvergewisserung über Notwendigkeit und Umfang des nachrichtendienstlichen Schutzes der Bundesrepublik fand weder 1949 noch 1989 statt. Stimmen, welche die in diesem Kontext bevorzugt als „Geheimdienste“3 bezeichneten Behörden bereits institutionell als Fremdkörper ${ }^{4}$ in einem demokratischen Rechtsstaat charakterisierten oder gar ihre Abschaffung ${ }^{5}$ forderten, wurden zwar immer wieder erhoben, sind aber stets vereinzelt geblieben. Gleichwohl war diese Rechtsmaterie stets „,vermintes Terrain“. ${ }^{6}$ In einer Gemengelage aus kaum aufzuklärenden Fakten, inhaltsar-

1 Schneider, Fernmeldegeheimnis und Fernmeldeaufklärung, 2020, S. 19.

2 Instruktiv Wegener, Der geheime Staat, 2006; pointiert Schmalenbach, Administrativer Verfassungsschutz: Bürger unter Beobachtung, in: Thiel (Hrsg.), Wehrhafte Demokratie, 2003, S. 415 (416).

$3 \mathrm{Zu}$ der rechtsbegrifflich möglichen und vor dem Hintergrund des Trennungsgebotes normativ angezeigten Abgrenzung von Geheim- (mit operativen Befugnissen) und Nachrichtendienst (ohne operative Befugnisse) vgl. Dietrich, Das Recht der Nachrichtendienste, in: ders./Eiffler (Hrsg.), Handbuch des Rechts der Nachrichtendienste, 2017, Kap. III $§ 3$ Rn. 7; Gröpl, Die Nachrichtendienste im Regelwerk der deutschen Sicherheitsverwaltung, 1993, S. 35 ff.; ein synonymer Gebrauch beider Begriffe ist gleichwohl verbreitet, vgl. etwa Kornblum, Rechtsschutz gegen geheimdienstliche Aktivitäten, 2011.

4 Exemplarisch Gössner, Geheimdienste als Fremdkörper der Demokratie, in: Paech/Spoo/ Butenschön (Hrsg.), Demokratie - wo und wie?, 2002, S. $167 \mathrm{ff}$.

5 Mit Blick auf den Verfassungsschutz zuletzt die Partei DIE LINKE, Wahlprogramm zur Bundestagswahl 2021 v. 19./20.6.2021, S. 118.

6 Unterreitmeier, Funktion und Zweckbindung der Nachrichtendienste, JZ 2021, 175 (176). 
men Normen und einer schwach ausgeprägten Kontrolle hatten sich die Dienste in einem Zustand zwischen administrativer Hinnahme und parlamentarisch-politischem Stillschweigen eingerichtet. ${ }^{7}$

Nachdem das Aufgaben- und Tätigkeitsprofil der Nachrichtendienste lange Zeit unterhalb des Radars der gesetzgeberischen und rechtswissenschaftlichen Aufmerksamkeit schwebte, ${ }^{8}$ hat es in der jüngeren Vergangenheit einen deutlichen Verrechtlichungsschub erfahren. Dieser erscheint umso erstaunlicher, als dass namentlich die Aufgaben und Befugnisse des Bundesnachrichtendienstes, um den es im Schwerpunkt gehen wird, nach einer anfänglich normativ ungesicherten Schwebelage ${ }^{9}$ zu Beginn der 1990er Jahre überhaupt erst auf eine gesetzliche Grundlage gestützt wurden. ${ }^{10}$ Hinter der gesetzgeberischen Dynamik stehen sicherheitspolitische Entwicklungen genauso wie Anstöße aus der Rechtsprechung. So hat vor allem das Bundesverfassungsgericht zur Verrechtlichung und rechtsstaatlichen Vergewisserung dieser opaken Materie maßgeblich beigetragen. Waren verfassungsrichterliche Judikate schon in der Vergangenheit „,bestimmende Impulsgeber"11 für legislatorische Aktivitäten auf dem Gebiet des Nachrichtendienst- und Verfassungsschutzwesens, hat das Bundesverfassungsgericht unlängst in mehreren, eng getakteten Entscheidungen den nachrichtendienstlichen Handlungsrahmen verfassungsrechtlich näher abgesteckt und die Funktion der Nachrichtendienste an veränderte Gefahren- und Bedrohungslagen einer zunehmend dynamischen wie digitalisierten Lebenswirklichkeit angepasst. In seinem Urteil zur Ausland-Ausland-Fernmeldeaufklärung vom 19. Mai $2020^{12}$ hat das Gericht nicht nur Maßstäbe für die Grundrechtsbindung der deutschen Staatsgewalt im Ausland gesetzt, sondern auch grundlegende Aussagen zur Funktion der Nachrichtendienste innerhalb der Sicherheitsarchitektur getroffen und detailgenaue Vorgaben für

7 Gusy, Architektur und Rolle der Nachrichtendienste in Deutschland, APuZ 18-19/2014, 9 (10).

8 Vgl. Gärditz, Straßprozeß und Prävention, 2003, S. 24: „führte lange Zeit ein Schattendasein“, ,in seinen dogmatischen Strukturen kaum beachtet“".

9 Gärditz, Grundrechtliche Grenzen strategischer Ausland-Ausland-Telekommunikationsaufklärung, JZ 2020, 825 (829); ders., Die Rechtsbindung des Bundesnachrichtendienstes bei Auslandstätigkeiten, DV 48 (2015), 463 (464).

10 Gesetz über den Bundesnachrichtendienst (BND-Gesetz - BNDG) v. 20.12.1990 (BGBl. I S. 2954).

11 Dietrich (Fn. 3), Kap. III § 3 Rn. 17; so auch im Untertitel des Beitrags von Körner, Die strategische Fernmeldeaufklärung im Lichte des BND-Urteils, StudZR-WissOn 1/2021, $127 \mathrm{ff}$.

12 BVerfGE 154, 152 - BND-Urteil = NJW 2020, 2235 = DÖV 2020, 691 (Ls.) = ZD 2020, 409 (mit Anm. Petri) $=$ JuS 2020, 705 (mit Anm. Sachs) $=$ JA 2020, 631 (mit Anm. Muckel) $=$ GSZ 2020, 173 (mit Anm. Dietrich). Vgl. des Weiteren die Besprechungsaufsätze von Aust, Auslandsaufklärung durch den Bundesnachrichtendienst, DÖV 2020, 715 ff.; Barczak, Vom rechtsfreien Raum zum raumlosen Recht?, BayVBl. 2020, 685 ff.; Durner, Schiffbruch der BND-Novelle 2016, DVB1. 2020, 951 ff.; Gärditz (Fn. 9), 825 ff.; Huber, Das BVerfG und die Ausland-Ausland-Fernmeldeaufklärung des BND, NVwZ-Beilage 2020, 3 ff.; Schmahl, Grundrechtsbindung der deutschen Staatsgewalt im Ausland, NJW 2020, 2221 ff.; Graulich, Befugnisse und Kontrolle des Bundesnachrichtendienstes bei der Fernmeldeaufklärung, GSZ 2021, 121 ff.; M. H. W. Möllers, Die Bindung der deutschen Staatsgewalt an die Grundrechte im Ausland, Jahrbuch Öffentliche Sicherheit 2020/2021, $752 \mathrm{ff}$. 
eine materiellrechtliche Neuordnung des Rechts der Nachrichtendienste gemacht, die sich in ihrem Gestaltungsanspruch nur schwer übertreffen lassen. ${ }^{13}$ In den kurz darauf ergangenen Beschlüssen zur Bestandsdatenauskunft ${ }^{14}$ und zum Antiterrordateigesetz ${ }^{15}$ hat das Gericht die von ihm entwickelten materiellen Maßgaben weiter zu konkretisieren und in die filigrane Matrix seiner mittlerweile zahlreichen Judikate ${ }^{16}$ zum Sicherheitsverfassungsrecht einzupassen gesucht. Bestand angesichts der zunehmenden Konvergenz der präventiv-polizeilichen und nachrichtendienstlichen Überwachungsstrategien in der Literatur Uneinigkeit darüber, ob und inwieweit die insbesondere im BKAG-Urteil entwickelten Grundsätze auf das Recht der Nachrichtendienste übertragbar sind, ${ }^{17}$ zeugen die jüngsten Entscheidungen von dem Bestreben des Senats, den im Jahr 2016 für das Polizeirecht eingeschlagenen Weg einer Rechtsprechungskonsolidierung in Bezug auf die Nachrichtendienste fortzusetzen und die Eingriffsschwellen anzugleichen. ${ }^{18}$

Eine administrative Emanzipation und normative Evolution im Recht der Nachrichtendienste sind die Folge: Der Bundesnachrichtendienst wird nicht länger auf seine überkommene Aufgabe als Informationsdienstleister für Regierung und Politik reduziert, sondern mit einer eigenständigen sicherheitsrechtlichen Aufgabe der Gefahrenfrüherkennung betraut, die er in eigener Verantwortung wahrzunehmen hat. Im Gefolge dessen stellt sich das Recht der Nachrichtendienste mehr und mehr als Querschnittsmaterie und Teil einer national wie international vernetzten Sicherheitsarchi-

13 Wie hier Gärditz (Fn. 9), 834.

14 BVerfGE 155, 119 - Bestandsdatenauskunft II = NJW 2020, 2699 (mit Anm. Holznagel $)=$ GSZ 2020, 182 (mit Anm. Löffelmann). Vgl. dazu ferner Graulich, Bestandsdatenauskunft II - Doppeltüren-Modell und Verhältnismäßigkeitsgrundsatz, NVwZ-Beilage 2020, $47 \mathrm{ff}$.

15 BVerfGE 156, 11 - Antiterrordateigesetz II = GSZ 2021, 25 (mit Anm. Löffelmann). Vgl. hierzu ferner Gusy, Das Trennungsprinzip zwischen Informationen von Nachrichtendiensten und Polizei, GSZ 2021, 141 ff.; Unterreitmeier, Es ist wieder da - das ,informationelle Trennungsprinzip“, DÖV 2021, $659 \mathrm{ff}$.

16 BVerfGE 100, 313 - Strategische Telekommunikationsüberwachung; 109, 279 - Großer Lauschangriff; 110, 33 - Telekommunikationsüberwachung nach dem AWG; 112, 304 GPS-Ortung; 113, 29 - Sicherstellung von Datenträgern; 113, 348 - Vorbeugende Telekommunikationsüberwachung nach dem NdsSOG; 115, 166 - Sicherstellung gespeicherter Telekommunikationsdaten; 115, 320 - Rasterfahndung; 118, 168 - Abfrage von Kontostammdaten; 120, 274 - Online-Durchsuchungen; 120, 378 - Automatisierte Kennzeichenerfassung I; 124, 43 - Beschlagnahme von E-Mails; 125, 260 - Vorratsdatenspeicherung; 129, 208 - TKÜ-Neuregelung; 130, 151 - Zuordnung dynamischer IP-Adressen; 133, 277 - Antiterrordatei; 141, 220 - BKA-Gesetz; 150, 309 - Automatisierte Kennzeichenerfassung II; 150, 244 - Automatisierte Kennzeichenerfassung III.

17 Näher Löffelmann, Heimliche Bild- und Tonaufzeichnungen, in: Dietrich/Eiffler (Hrsg.), Handbuch des Rechts der Nachrichtendienste, 2017, Kap. VI $\$ 3$ Rn. 1 ff.; Unterreitmeier, Überwachung durch Polizei oder Nachrichtendienste - kein Unterschied?, GSZ 2018, 1 ff.; ders., Folgewirkungen des BKAG-Urteils für die Nachrichtendienste?, NWVBl. 2018, $227 \mathrm{ff}$.

18 Dies hatte der Berichterstatter des BKAG- und BNDG-Urteils in der Zwischenzeit bereits deutlich gemacht, vgl. Masing, Nachrichtendienste im freiheitlichen Rechtsstaat, in: Dietrich/Gärditz/Graulich u.a. (Hrsg.), Nachrichtendienste im demokratischen Rechtsstaat, 2018, S. 3 (7 ff.); ders., Überwachung durch Polizei oder Nachrichtendienst, GSZ 2018, 6 (6); daran anschließend wiederum Unterreitmeier (Fn. 6), 176. 
tektur dar. ${ }^{19}$ Das Nachrichtendienstrecht wird dabei in den im Sicherheitsrecht generell zu beobachtenden Trend zur permanenten Reformierung und Novellierung hineingezogen und stellt sich als ein zunehmend instabiles Regelungsfeld dar. ${ }^{20}$ Zugleich büßt es seinen Charakter als Sondermaterie für spionageaffine Praktiker ein. Dennoch findet sich die These vom Nachrichtendienstrecht als übergreifendem Systemansatz nach wie vor nur vereinzelt. ${ }^{21}$ Die aufgrund der Geheimhaltungsbedürftigkeit erheblich eingeschränkten Möglichkeiten, individuellen Rechtsschutz gegen die Überwachungstätigkeit der Nachrichtendienste zu erlangen, ${ }^{22}$ hatten zur Folge, dass sich dieses Rechtsgebiet in dem für das Sicherheitsrecht charakteristischen Wechselspiel ${ }^{23}$ von Gesetzgebung, gerichtlicher Kontrolle, behördlicher Anwendungspraxis und rechtswissenschaftlicher Aufarbeitung nur in sehr überschaubarem Maße ausformen konnte. ${ }^{24}$ Des Weiteren ist zu beachten, dass das Recht der Nachrichtendienste ein vergleichsweise traditionsloses Rechtsgebiet ist, das - anders als das Polizei- und Ordnungsrecht - nicht auf eine lange Entstehungs- und Entwicklungsgeschichte zurückblicken kann. Zwar stammt das BVerfSchG bereits aus dem Jahr 1950, ${ }^{25}$ doch enthielt dieses anfangs nur eine Aufgabenbestimmung für das Bundesamt für Verfassungsschutz (BfV), verbunden mit der negativen Abgrenzung der Befugnisse zur Polizei. Die rechtliche Relevanz des Tätigkeitsspektrums der Nachrichtendienste, deren Proprium gerade darin besteht, rationalisierend Daten und Informationen als kognitive Herrschaftsinstrumente zu generieren und zu verarbeiten, ${ }^{26}$ wurde hingegen erst durch das Volkszählungsurteil des Bundesverfassungsgerichts aus dem Jahr $1983^{27}$ erkennbar. Mit der Begründung eines informationellen Selbstbestimmungsrechts konnte das Erheben, Sammeln und Speichern von Daten und Informationen nicht mehr als eine grundrechtsindifferente Vorstufe zum operativen (Polizei-) Handeln durchgehen. ${ }^{28}$ Im Anschluss daran wurden im Jahr 1990 die Befugnisse des BfV gesetzlich fixiert und für die Tätigkeit von Bundesnachrichtendienst (BND) und Militärischem Abschirmdienst (MAD) die formell-gesetzlichen Grundlagen nachgeschoben.

19 Ansätze in diese Richtung schon bei Gröpl (Fn. 3), S. 272 ff.; instruktiv zuletzt Banzhaf, Die Ämter für Verfassungsschutz als Präventionsbehörden, 2021; überblicksweise Gusy, Vom neuen Sicherheitsbegriff zur neuen Sicherheitsarchitektur, VerwArch 101 (2010), $309 \mathrm{ff}$.

20 Allgemein für das Sicherheitsrecht Bäcker, Kriminalpräventionsrecht, 2015, S. $1 \mathrm{f}$.

21 Gusy, in: Schenke/Graulich/Ruthig (Hrsg.), Sicherheitsrecht des Bundes, 2. Aufl. 2019, BNDG, Vorb. Rn. 9, m.w.N.

22 BVerfGE 154, 152, Rn. 273; näher Buchberger, Gerichtlicher Rechtsschutz gegen nachrichtendienstliche Aktivitäten?, in: Dietrich/Gärditz/Graulich u.a. (Hrsg.), Nachrichtendienste im demokratischen Rechtsstaat, 2018, S. $107 \mathrm{ff}$.

23 Vgl. Wolff, Verfassung in ausgewählten Teilrechtsordnungen: Sicherheitsrecht, DVB1. 2017, 1076 (1077, 1084), der den Gesetzgeber hier ,in ständiger Zwiesprache mit den Verfassungsgerichten" sieht.

24 BVerfGE 141, 220, Rn. 94; 154, 152, Rn. 137; Gusy (Fn. 21), BNDG, Vorb. Rn. 13.

25 Gesetz über die Zusammenarbeit des Bundes und der Länder in Angelegenheiten des Verfassungsschutzes v. 27.9.1950 (BGB1. I S. 682).

26 Gärditz, Sicherheitsverfassungsrecht und technische Aufklärung durch Nachrichtendienste, EuGRZ 2018, 6 (22), m.w.N.

27 BVerfGE 65, 1 (41 ff.).

28 Gusy (Fn. 21), BNDG, Vorb. Rn. 6. 
Ungeachtet des hiermit eingeleiteten Prozesses nachholender Verrechtlichung hat diese noch kein kohärentes Konzept hervorgebracht. ${ }^{29}$ Eine spezifisch nachrichtendienstrechtliche Dogmatik konnte sich bislang allenfalls fragmentarisch und erratisch herausbilden. ${ }^{30}$ Vom Grad der Verrechtlichung des Strafprozess- und Polizeirechts ist das Recht der Nachrichtendienste noch immer weit entfernt. ${ }^{31}$ Aktuell bildet das Nachrichtendienstrecht ein der Konsolidierung und Kodifizierung harrendes Rechtsgebiet. ${ }^{32}$ Weder das als „Meilenstein“ geltende BNDG-Urteil des Bundesverfassungsgerichts noch die hierauf reagierende Reform des Nachrichtendienstrechts aus dem Frühjahr 2021 vermochten daran bislang etwas zu ändern. Obschon gerade letztere den Anspruch einer ,grundlegenden Novelle“ ${ }^{“ 33}$ verfolgte, bleibt sie in wesentlichen Teilen „Flickwerk“"34 und kann nicht den Blick darauf verstellen, dass dem Recht der Nachrichtendienste bislang insgesamt „eine Ordnungsidee fehlt ${ }^{\text {“ }}{ }^{35}$ Die verfassungsrechtlichen und normsystematischen Defizite im geltenden Nachrichtendienstrecht lassen sich durch punktuelle Reparaturen einzelner Normen nicht beheben. Die überfällige Gesamtreform und Bereinigung des Nachrichtendienstrechts stehen noch aus. ${ }^{36}$ Wie das Sicherheitsrecht im Allgemeinen ${ }^{37}$ befindet sich das Recht der Nachrichtendienste somit in einer Übergangs- und Findungsphase, ${ }^{38}$ die von teils divergierenden Entwicklungstendenzen gekennzeichnet ist.

Im Folgenden soll zunächst ein Blick auf das Urteil des Bundesverfassungsgerichts zum BNDG geworfen werden (unten B.), um ausgehend hiervon die aktuellen Emanzipations- und Evolutionstendenzen im Recht der Nachrichtendienste in den Blick zu

29 Wie hier Wegener, Konstitutionalisierung und Gegenbewegungen im Sicherheitsrecht, VVDStRL 75 (2016), 293 (320 f.).

30 Lindner/Unterreitmeier, Grundlagen einer Dogmatik des Nachrichtendienstrechts, DÖV 2019, 165 (165).

31 Gusy (Fn. 21), BNDG, Vorb. Rn. 10.

32 Zum Rechtsgebietscharakter näher Dietrich (Fn. 3), Kap. III 33 Rn. 17 ff.; Gusy, Reformperspektiven des Rechts der Nachrichtendienste, in: Dietrich/Gärditz/Graulich u.a. (Hrsg.), Reform der Nachrichtendienste zwischen Vergesetzlichung und Internationalisierung, 2019, S. 19 (24 ff.).

33 So die Begründung des Gesetzes zur Änderung des BND-Gesetzes zur Umsetzung der Vorgaben des Bundesverfassungsgerichts sowie des Bundesverwaltungsgerichts, vgl. BT-Drs. 19/26103, S. 3.

34 Gärditz, Bundesnachrichtendienst semper reformanda, DVB1. 2021, 905 (913). Dies war freilich auch dem Zeitpunkt der Reform kurz vor Ablauf der Legislaturperiode geschuldet, vgl. dazu ders., Öffentliche Anhörung des Innenausschusses v. 22.2.2021, ProtokollNr. 19/120, S. 9.

35 Dietrich (Fn. 3), Kap. III $\S 3$ Rn. 71; ders., Schriftliche Stellungnahme an den Innenausschuss v. 21.2.2021, Ausschuss-Drs. 19(4)731 G, S. 4, 23.

36 Stattdessen reiht sich eine Reform an die nächste, mit der Folge, dass die Devise „Nach der Reform ist vor der Reform“ zu einem regelrechten Programmsatz des Nachrichtendienstrechts avanciert ist, vgl. nur Dietrich, Reform der parlamentarischen Kontrolle der Nachrichtendienste als rechtsstaatliches Gebot und sicherheitspolitische Notwendigkeit, ZRP 2014, 205 (208); Aust (Fn. 12), 715, 723 („Reform der Reform“); Gärditz (Fn. 34), 913 f.

37 Vgl. Kniesel, Sicherheitsrecht - Anmerkungen zu einem Rechtsgebiet in der Findungsphase, Die Polizei 2018, 265.

38 Wie hier Löffelmann, Die Ausland-Ausland-Fernmeldeaufklärung, in: Dietrich/Gärditz/ Graulich u.a. (Hrsg.), Reform der Nachrichtendienste zwischen Vergesetzlichung und Internationalisierung, 2019, S. 33 (33): „im Umbruch begriffen“. 
nehmen und aufzuzeigen, inwieweit dieses Recht zugleich ,in einem Erosionsprozess befangen" ${ }^{\text {39 }}$ ist (unten C.).

\section{B. Nachrichtendienstrecht aus der Hand des Bundesverfassungsge- richts}

Hatte der Prozess der Konstitutionalisierung aller Teilbereiche der Rechtsordnung bis vor Kurzem noch einen relativ weiten Bogen um das Recht der Nachrichtendienste gemacht, ${ }^{40}$ hat das Bundesverfassungsgericht diese Lücke mit seinem BNDG-Urteil vom 19. Mai 2020 geschlossen und mit detaillierten, aus der Verfassung gewonnenen Verrechtlichungsvorgaben bis hin zu einem institutional setting ganzer Kontrollbehörden gefüllt. Auf eine Individualverfassungsbeschwerde der in Paris ansässigen Nichtregierungsorganisation Reporters sans frontières und von sechs investigativ tätigen in- und ausländischen Journalistinnen und Journalisten hat das Gericht die Regelungen zur Ausland-Ausland-Fernmeldeaufklärung, die erst Ende 2016 in Reaktion auf die Enthüllungen des NSA-Untersuchungsausschusses in das BNDG eingefügt worden waren, ${ }^{41}$ für verfassungswidrig erklärt. Das Urteil gilt - insbesondere mit Blick auf seine Aussagen zur extraterritorialen Geltung der Grundrechte - als ,gleichermaßen naheliegend wie bahnbrechend“. ${ }^{42}$ In der Tat war in der Literatur vielstimmig auf die Grundrechtsbindung des BND bei der Auslandsaufklärung hingewiesen und allenfalls eine punktuelle Absenkung des Schutzniveaus diskutiert worden. ${ }^{43}$ Gleichwohl war von einem „,der spektakulärsten Urteile der jüngeren deutschen Rechtsgeschichte "44 und einem ,Meilenstein“"45 in der verfassungsgerichtlichen Grundrechtsjudikatur die Rede, das in seiner Wirkmächtigkeit „mit der berühmten Lüth-Entscheidung vergleichbar" ${ }^{\star 46}$ sei. Kritischere Stimmen verweisen darauf, dass das BNDG-Urteil zwar

39 In Bezug auf die Funktionsweise der Nachrichtendienste Wegener (Fn. 29), 313.

40 So die treffende Feststellung bei Schwander, Wessen Freiheit? Auslandsnachrichtendienste und Grundrechte, in: Brings-Wiesen/Ferreau (Hrsg.), 40 Jahre „Deutscher Herbst“, 2019, S. 73 (74). Mit Ansätzen in diese Richtung Wolff (Fn. 23), 1080, der aber einräumen muss, dass die bisherigen Überlegungen zu einer „relativ geringen rechtlichen Steuerung der Nachrichtendienste" geführt haben.

41 Durch Gesetz zur Ausland-Ausland-Fernmeldeaufklärung v. 23.12.2016 (BGBl. I S. 3346). Zu der BNDG-Novelle vgl. Gärditz, Die Reform des Nachrichtendienstrechts des Bundes, DVB1. 2017, 525 ff.; Graulich, Reform des Gesetzes über den Bundesnachrichtendienst, KriPoZ 2017, 43 ff.; Hölscheidt, Das neue Recht des Bundesnachrichtendienstes, JURA 2017, 148 ff.; Marxsen, Strategische Fernmeldeaufklärung, DÖV 2018, 218 ff.

42 Schmahl (Fn. 12), 2221.

43 Vgl. auszugsweise Schwander, Extraterritoriale Wirkungen von Grundrechten im Mehrebenensystem, 2019, S. 175 ff., 262 ff. et passim; vgl. zusammenfassend auch ders. (Fn. 40), S. 73 ff.; Bäcker, Strategische Telekommunikationsüberwachung auf dem Prüfstand, K\&R 2014, 556 (559 ff.); Becker, Grundrechtliche Grenzen staatlicher Überwachung zur Gefahrenabwehr, NVwZ 2015, 1335 (1339); Löffelmann (Fn. 38), S. 35 ff.; Wegener (Fn. 29), 320 f.; mit deutlicheren Abstufungen noch Gärditz (Fn. 9), 467 ff., 474 ff.

44 Mascolo/Steinke, Eingeschränktes Lauschvermögen, SZ v. 6./7.6.2020, S. 8.

45 Huber (Fn. 12), 9; Schmahl (Fn. 12), 2221.

46 Schmahl (Fn. 12), 2221. 
auf die Grundfrage nach der extraterritorialen Grundrechtsgeltung „eine Antwort“ geliefert, aber mit Relativierungen hinsichtlich des Schutzumfangs zugleich „,viele neue Fragen“" aufgeworfen und unbeantwortet gelassen habe. ${ }^{47}$ Andere sehen in der Grundrechtsgeltung ohne jede personale und territoriale Begrenzung einen grundrechtstheoretischen „Einschnitt“, ${ }^{48}$ der verkenne, dass die räumliche Begrenzung politischer Ordnungen keiner nationalistischen, sondern - im Gegenteil - einer liberalen Vorstellung des Rechts entspringe. Schließlich wird befürchtet, dass die Entscheidung „schwerwiegende Auswirkungen auf die Handlungsfähigkeit, die Flexibilität und die Kooperationen des BND mit anderen Geheimdiensten" haben wird. ${ }^{49}$

Obschon mit der Feststellung der extraterritorialen Grundrechtsgeltung feststand, dass wesentliche Teile des BNDG bereits aus formellen Gründen wegen eines Verstoßes gegen das Zitiergebot verfassungswidrig waren (unten I.), hat das Bundesverfassungsgericht einen Großteil der Entscheidung darauf verwendet, materiellrechtliche Vorgaben für eine verfassungskonforme gesetzliche Neuregelung zu entwickeln (unten II.).

\section{Grundrechtsbindung im Ausland gegenüber Ausländern}

Die „Kernfrage“50 des BNDG-Verfahrens bestand darin, ob die Grundrechte des Grundgesetzes deutsche Staatsgewalt nach Art. 1 Abs. 3 GG nur dann binden, wenn diese innerhalb der deutschen Staatsgrenzen agiert oder zumindest eine Inland-Ausland-Kombination ${ }^{51}$ vorliegt. In diesem Fall wäre ein reiner Auslandssachverhalt wie das Instrument der strategischen Ausland-Ausland-Fernmeldeaufklärung, die nicht auf die Überwachung einzelner Personen, sondern auf die Aufklärung von Szenarien mit grundsätzlicher sicherheitspolitischer Bedeutung im Rahmen der sogenannten Signals Intelligence (SIGINT) zielt, ${ }^{52}$ nicht am Maßstab der Art. 1-19 GG zu messen gewesen. Eine ausdrückliche Befugnisnorm zur Erhebung personenbezogener Daten vom Ausland aus enthielt das BND-Gesetz bewusst nicht; $\S 7$ Abs. 1 BNDG normierte lediglich die weitere Verarbeitung vom Ausland aus erhobener Daten, indem er an die Erhebung von Daten vom Inland aus und deren Verarbeitung in $\S 6$ BNDG anknüpfte.

Der BND-Gesetzgeber ging 2016 davon aus, dass es einer dem rechtsstaatlichen Vorbehalt des Gesetzes Rechnung tragenden, spezialgesetzlichen Eingriffsgrundlage

47 Schwander, Eine Antwort, viele neue Fragen: Das BND-Urteil des Bundesverfassungsgerichts, VerfBlog, 2020/5/23, https://verfassungsblog.de/eine-antwort-viele-neue-fragen/.

48 Meinel, Globalisierung der Grundrechte?, NJW-aktuell 24/2020, 3.

49 So das Mitglied des PKGr Andrea Lindholz (CSU), zitiert nach FAZ v. 24.5.2020, S. 4.

50 So der Berichterstatter, Johannes Masing, auf dem 1. Symposium zum Recht der Nachrichtendienste am 3./4.11.2016, zitiert nach dem Tagungsbericht von Schwander, „Transparenz der Intransparenz" - Bericht über das erste Symposium zum Recht der Nachrichtendienste, DÖV 2017, 420 (421).

51 Vgl. insoweit BVerfGE 6, 290 (295) - Zustimmungsgesetze; 31, 58 (67) - Spanier-Beschluss; 57, 9 (23 f.) - Einlieferungsersuchen.

52 Gärditz, Strategische Fernmeldebeschränkung und Netzknotenüberwachung für den Verfassungsschutz?, in: FS Kurt Graulich, 2019, S. 153 (153). 
für Auslandserhebungen nicht bedürfe. ${ }^{53}$ Weil hier keine Bindung an die Grundrechte des Grundgesetzes bestehe, könnten Datenerhebungen allein auf die rein final gestaltete Aufgabenzuweisungsnorm des $\S 1$ Abs. 2 Satz 1 BNDG gestützt werden, nach welcher der BND zur Gewinnung von Erkenntnissen über das Ausland, die von außen- und sicherheitspolitischer Bedeutung für die Bundesrepublik Deutschland sind, die erforderlichen Informationen sammelt und auswertet. Wie im NSA-Untersuchungsausschuss deutlich wurde, hatte der BND bereits vor der Gesetzesnovelle im Jahr 2016 den Anwendungsbereich der spezialgesetzlichen Ermächtigungsgrundlagen (§5 G 10 a.F.) mit dem Schutzbereich des Grundrechts aus Art. 10 GG verkoppelt und seine Ermächtigung zur Auslandsaufklärung ,gewissermaßen um dieses Grundrecht herum[geschnitten]". ${ }^{54}$ Diese Strategie war indes nur so lange tragfähig, wie eine Anwendung des Art. 10 GG nicht in Betracht kam, denn eine schlichte Aufgabenzuweisung genügt nicht den Anforderungen, die sich aus den Geboten der Bestimmtheit, Normenklarheit und Verhältnismäßigkeit an eine Befugnis- und Eingriffsermächtigung stellen. ${ }^{55}$

Im BNDG-Urteil vom 19. Mai 2020 hat das Bundesverfassungsgericht nun klargestellt, dass die Grundrechte des Grundgesetzes den BND und den seine Befugnisse regelnden Gesetzgeber unabhängig davon binden, ob der Dienst im Inland oder im Ausland tätig wird. ${ }^{56}$ Art. 1 Abs. 3 GG enthalte seinem Wortlaut nach keine Beschränkung auf das deutsche Staatsgebiet. Eine Ausnahme von der Grundrechtsgeltung könne auch nicht aus einem dahingehenden unausgesprochen konsentierten Grundverständnis bei Entstehung des Grundgesetzes hergeleitet werden. Art. 1 Abs. 3 GG ziele in Reaktion auf die nationalsozialistische Gewalt- und Willkürherrschaft vielmehr auf eine umfassende, in der Menschenwürde wurzelnde Grundrechtsbindung und sei bereits 1949 in die Überzeugung eingebettet gewesen, dass die Bundesrepublik in der internationalen Staatengemeinschaft ihren Platz als rechtsstaatlicher Partner finden müsse. Dies komme schon in der Präambel sowie in Art. 1 Abs. 2 GG und Art. 24 und 25 GG zum Ausdruck. Der Anspruch eines lückenlosen, den Menschen in den Mittelpunkt stellenden Grundrechtsschutzes spreche dafür, dass die Grundrechte immer dann schützen sollen, wenn der deutsche Staat handelt und damit potentiell Schutzbedarf auslösen kann - „unabhängig davon, an welchem Ort und gegenüber wem". 57

Mit der umfassenden Grundrechtsbindung hat das Gericht auch auf ein gewandeltes Aufgaben- und Anforderungsprofil der Nachrichtendienste im 21. Jahrhundert reagiert. So schaffe die lückenlose Bindung nach Art. 1 Abs. 3 GG die Voraussetzungen dafür, um auch Grundrechtsgefährdungen durch neue technische Entwicklungen und sich hierdurch ergebende Kräfteverschiebungen Rechnung tragen zu können. ${ }^{58}$ Die nachrichtendienstliche Auslandsaufklärung habe für die Handlungsfähigkeit der Bun-

53 Vgl. BT-Drs. 18/9041, S. 25.

54 Bäcker, Der BND baut sich einen rechtsfreien Raum: Erkenntnisse aus dem NSA-Untersuchungsausschuss, VerfBlog, 2015/1/19, https://verfassungsblog.de/der-bnd-baut-sich-einenrechtsfreien-raum-erkenntnisse-aus-dem-nsa-untersuchungsausschuss/.

55 Vgl. BVerfGE 100, 313 (372 ff., 386 ff.).

56 BVerfGE 154, 152, Rn. 87.

57 BVerfGE 154, 152, Rn. 89.

58 BVerfGE 154, 152, Rn. 105 ff. 
desrepublik Deutschland in der Außen- und Sicherheitspolitik seit jeher eine erhebliche Bedeutung gehabt. Im Zuge der Entwicklung der Informationstechnik und der Internationalisierung hätten sich Bedeutung und Bedingungen der Auslandsfernmeldeaufklärung als eines zentralen Elements der nachrichtendienstlichen Auslandstätigkeit jedoch grundlegend geändert. So könnten internationale Aktivitäten heute für das Gemeinwesen insgesamt destabilisierende Wirkung entfalten, wie exemplarisch in Cyberangriffen, international organisierter Kriminalität (z.B. Menschenhandel oder Geldwäsche) und internationalem Terrorismus sichtbar werde. ${ }^{59}$

In formeller Hinsicht verstießen die angegriffenen Vorschriften gegen das Zitiergebot aus Art. 19 Abs. 1 Satz 2 GG. ${ }^{60}$ Zwar nennt $\S 3$ Abs. 3 BNDG das Fernmeldegeheimnis des Art. 10 Abs. 1 GG als eingeschränktes Grundrecht; die Norm bezog sich jedoch weder nach ihrem Wortlaut (,,insoweit"), noch systematisch oder nach dem erklärten Willen des Normgebers auf die Vorschriften über die Ausland-Ausland-Fernmeldeaufklärung.

\section{Vorgaben für die Neuregelung}

Mit der Feststellung der formellen Verfassungswidrigkeit hätte das Gericht es bewenden lassen können. Dass der Senat dies nicht getan und die folgenden knapp 200 Randnummern der Entscheidung darauf verwendet hat, die Unvereinbarkeit der angefochtenen Vorschriften auch in materieller Hinsicht festzustellen, überrascht mit Blick auf die jüngere sicherheitsrechtliche Rechtsprechung des Bundesverfassungsgerichts allerdings nicht. ${ }^{61}$ Wie zuletzt in den Entscheidungen zum $\mathrm{BKAG}^{62}$ und zur automatisierten Kfz-Kennzeichenkontrolle ${ }^{63}$ lässt sich das Gericht die Chance nicht entgehen, dem Gesetzgeber Vorgaben für eine verfassungskonforme Neuregelung mit einem hohen Grad an Detailverliebtheit ins Stammbuch zu schreiben, die es im Wege der Grundrechtsabwägung gewonnen haben will. ${ }^{64}$ Diese Vorgehensweise mag man als praxisfremd, judicial activism oder Überkonstitutionalisierung des Sicherheitsrechts kritisieren, ${ }^{65}$ zumal sie den einfachen Gesetzgeber ein Stück weit aus der politischen Verantwortung entlässt, weil dieser angesichts der kleinteiligen verfassungsgerichtlichen Vorgaben rechtlich gut beraten ist, diese entweder als Textbausteine oder gar eins-zu-eins zu übernehmen, will er nicht sehenden Auges eine neuerliche verfassungsgerichtliche Kassation riskieren. Der Berichterstatter rechtfertigt die detaillierten Vorgaben maßgeblich mit der Heimlichkeit der jeweils in Rede stehenden Eingriffe,

59 BVerfGE 154, 152, Rn. 107.

60 BVerfGE 154, 152, Rn. $134 \mathrm{f}$.

61 Von einem „,bekannten Monumentalstil des Berichterstatters“ spricht Gärditz (Fn. 9), 834.

62 BVerfGE 141, 220, Rn. $98 \mathrm{ff}$.

63 BVerfGE 150, 309, Rn. 70 ff.; 150, 244, Rn. 81 ff.

64 Gärditz (Fn. 9), 832; Meinel (Fn. 48), 3.

65 Statt vieler Möstl, Das Bundesverfassungsgericht und das Polizeirecht, DVB1. 2010, 808 (816); zu der Frage einer verfassungsrichterlichen Überkonstitutionalisierung Bäcker, Sicherheitsverfassungsrecht, in: Herdegen/Masing/Poscher u.a. (Hrsg.), HVerfR, 2021, § 28 Rn. 184 ff.; ders., Terrorismus und Sicherheitsverfassungsrecht in Deutschland, in: Scherzberg/Can/Doğan (Hrsg.), Der Rechtsstaat in Zeiten von Notstand und Terrorabwehr, 2019, S. 117 (149 ff.). 
weshalb verfassungsgerichtlich „so viele Schutzkautelen“ gegenüber dem Gesetzgeber zu formulieren wären, dass damit eine ,gewisse Freiheitlichkeit, ein Schutz auf Dauer" gewährleistet sei. ${ }^{66}$

Anstelle sich auf einige wenige, ebenso grundlegende wie begrenzte Ausführungen zur materiellen Neugestaltung der Ausland-Ausland-Fernmeldeaufklärung zu beschränken und sich dabei an den durchaus gehaltvollen normativen Festlegungen zu orientieren, die das Grundgesetz dem Recht der Nachrichtendienste widmet (vgl. Art. 45 d, 73 Abs. 1 Nr. 10 lit. b, 87 Abs. 1 Satz 2 GG), ${ }^{67}$ greift das Gericht ausschließlich auf den Verhältnismäßigkeitsgrundsatz zurück. Dieser dient als Kreativitätsreserve für eine verfassungsrichterliche Rechtsgestaltung de lege ferenda. ${ }^{68}$ Das BNDGUrteil bestätigt damit einmal mehr die These, „dass sich allmählich eine eigene - vom geschriebenen Verfassungsrecht emanzipierte und letztlich allein auf Erwägungen der Verhältnismäßigkeit gründende - Sicherheitsverfassung ausdifferenziert".69 Danach hat der Gesetzgeber einschränkende Maßgaben zum Volumen der für die jeweiligen Übertragungswege auszuleitenden Daten vorzugeben und sicherzustellen, dass das von der Überwachung abgedeckte geographische Gebiet begrenzt bleibt. ${ }^{70}$ Darüber hinaus muss er rechtsstaatliche Einhegungen schaffen, die die Datenerhebung und Datenverarbeitung näher strukturieren und begrenzen. Hierzu gehören insbesondere Regelungen zum Einsatz von Filtertechniken (Aussonderung von Daten aus der Inlandskommunikation), ${ }^{71}$ zu den Überwachungszwecken, ${ }^{72}$ zur Gestaltung des Überwachungsverfahrens, ${ }^{73} \mathrm{zu}$ einem fokussierten Umgang mit Suchbegriffen, ${ }^{74}$ zum Schutz von Vertraulichkeitsbeziehungen ${ }^{75}$ sowie des Kernbereichs privater Lebensgestaltung. ${ }^{76}$ Hinzu kommen Anforderungen an die Datenübermittlung ${ }^{77}$ sowie an die Kooperation mit ausländischen Nachrichtendiensten. ${ }^{78}$ Diesen verfassungsrichterlichen „Segelanweisungen“, die den legislatorischen Gestaltungsspielraum annähernd auf Null reduzierten, ist der Gesetzgeber mittlerweile ,nachgerade buchstabengetreu“79 im Rahmen einer ebenso umfang- wie facettenreichen Reform des Nachrichtendienstrechts nachgekommen. ${ }^{80}$

66 Vgl. Masing, im Interview bei: Die Justizreporter*innen, abrufbar unter: https://www.ardau diothek.de/die-justizreporter-innen/verfassungsrichter-johannes-masing-ueber-meinungsfre iheit-schmaehkritik/77272774, ab 30:50 Minuten.

67 Näher zu diesen Lindner/Unterreitmeier (Fn. 30), 166 ff.

68 Ähnlich Gärditz (Fn. 9), 834; Graulich (Fn. 12), 122.

69 Gärditz (Fn. 26), 7.

70 BVerfGE 154, 152, Rn. 169.

71 BVerfGE 154, 152, Rn. 170-174.

72 BVerfGE 154, 152, Rn. 175-177.

73 BVerfGE 154, 152, Rn. 178-184. Hierzu näher unter C. II. 2.

74 BVerfGE 154, 152, Rn. 185-190.

75 BVerfGE 154, 152, Rn. 193-198.

76 BVerfGE 154, 152, Rn. 199-207.

77 BVerfGE 154, 152, Rn. 211-242.

78 BVerfGE 154, 152, Rn. 243-264. Hierzu näher unter C. III. 2.

79 Beide Zitate nach Gärditz (Fn. 34), 905, 906.

80 Durch Gesetz zur Änderung des BND-Gesetzes zur Umsetzung der Vorgaben des Bundesverfassungsgerichts sowie des Bundesverwaltungsgerichts v. 19.4.2021, BGBl. I S. 771. 


\section{Erosions-, Emanzipations- und Evolutionstendenzen im Recht der Nachrichtendienste}

Ausgehend von den verfassungsgerichtlichen Maßgaben und ihrer Umsetzung durch die BNDG-Reform im Frühjahr 2021 sollen im Folgenden die wesentlichen Entwicklungslinien im Nachrichtendienst- und Verfassungsschutzrecht analysiert und konturiert werden. Bislang ist es weder in der Rechtsprechung des Bundesverfassungsgerichts noch im Rahmen der gesetzgeberischen Reformen gelungen, das Nachrichtendienstrecht zu einem kohärenten Baustein auszuformen und diesen passgenau in das facettenreiche Mosaik des Sicherheits(verfassungs)rechts einzufügen. Das Recht der Nachrichtendienste verharrt vielmehr in einem Schwebezustand zwischen konstitutioneller Stabilisierung und permanenter Reformierung. Erosions-, Emanzipations- und Evolutionstendenzen sind die Folge.

\section{Präzisierung des nachrichtendienstlichen Auftrags}

Nach klassischem Verständnis sind Nachrichtendienste politische Frühwarnsysteme ${ }^{81}$ und Informationsdienstleister ${ }^{82}$ der Regierung. Sie haben - begrifflich wie von Gesetzes wegen ${ }^{83}$ - den Auftrag, Informationen auf politischem, militärischem und wirtschaftlichem Gebiet zu sammeln, auszuwerten und für die politische Führung eines Staates bereitzustellen. ${ }^{84}$ Der Aufgabencharakter der Nachrichtendienste hat sich indes in der jüngeren Vergangenheit gewandelt und unter den Bedingungen der Informationstechnologie sowie der Internationalisierung von Handlungszusammenhängen „einen qualitativen Sprung erfahren“" ${ }^{85}$ Er erschöpft sich nicht mehr in der politischen Aufklärung. Diese wird vielmehr ergänzt durch eine dezidiert sicherheitsrechtliche Funktion der Gefahrenfrüherkennung, die als eigenständige dritte Säule neben die repressive sowie die präventiv-polizeiliche Sicherheitsgewährleistung tritt und die staatliche Sicherheitsarchitektur vervollständigt. ${ }^{86}$

\section{Doppelfunktionalität: Politische Information und Gefahrenfrüherkennung}

Ungeachtet der schon zu diesem Zeitpunkt gesetzlich verankerten Regelungen, die ein weitergehendes Funktionsverständnis nahelegten, reduzierte das Bundesverfassungsgericht in seinem ersten Antiterrordatei-Urteil aus dem Jahr 2013 den Aufklärungs-

81 Gusy, Polizei und Nachrichtendienste, in: Kugelmann (Hrsg.), Polizei und Menschenrechte, 2019, S. $430(433,435)$.

82 BT-Drs. 18/4654, S. 31.

83 Vgl. § 3 Abs. 1 BVerfSchG; § 1 Abs. 2 Satz 1 BNDG; § 1 Abs. 1 Satz 1 MADG.

84 Fassbender, Wissen als Grundlage staatlichen Handelns, in: Isensee/Kirchhof (Hrsg.), HStR, Bd. 4, 3. Aufl. 2006, § 76 Rn. 111.

85 Masing, in: Dietrich/Gärditz/Graulich u.a. (Fn. 18), S. 4.

$86 \mathrm{Zu}$ dieser Dreigliedrigkeit der Sicherheitsgewährleistung schon Schoch, Polizei- und Ordnungsrecht, in: ders. (Hrsg.), Besonderes Verwaltungsrecht, 2018, Kap. 1 Rn. 30; Wolff (Fn. 23), $1077 \mathrm{f}$. 
auftrag des Bundesnachrichtendienstes noch auf die sogenannte politische Vorfeldaufklärung. ${ }^{87}$ Ziel ihrer Arbeit sei nicht die operative Gefahrenabwehr, sondern ausschließlich die politische Information. In Form von Lageberichten, Analysen und Berichten über Einzelerkenntnisse solle ,die Bundesregierung in den Stand gesetzt werden, Gefahrenlagen rechtzeitig zu erkennen und ihnen - politisch - zu begegnen". ${ }^{88}$ Dieses enge Funktionsverständnis stieß in der Literatur auf Kritik, weil es die praktisch wie rechtlich bedeutsame Rolle der Nachrichtendienste im behördlichen Netzwerk der Sicherheitsgewährleistung nahezu vollständig ausblendete. ${ }^{89}$ Die nachrichtendienstrechtlichen Fachgesetze enthielten bereits $\mathrm{zu}$ diesem Zeitpunkt spezifische Übermittlungsvorschriften (vgl. §20 BVerfSchG, § 11 Abs. 2 MADG, § 24 Abs. 3 BNDG, $\S 7$ G 10), die den Informationsaustausch mit Strafverfolgungs- und Sicherheitsbehörden sowie den Bundesämtern für Wirtschaft und Ausfuhrkontrolle (BAFA) und für Sicherheit in der Informationstechnik (BSI) regelten. ${ }^{90}$ Diese Übermittlungsregelungen sind „notwendige Konsequenz“91 der organisatorischen Trennung. Sie sind Ausdruck eines arbeitsteiligen Zusammenwirkens zwischen institutionell zu trennenden, sich aber funktional ergänzenden Einrichtungen staatlicher Sicherheitsgewährleistung. ${ }^{92}$ In diesem Kontext fungieren die Nachrichtendienste schon seit längerem als Akteure staatlicher Sicherheitsgewährleistung. Sie sind jedenfalls insoweit etablierter Bestandteil der Sicherheitsverwaltung. ${ }^{93}$

Von seinem restriktiven nachrichtendienstlichen Funktionsverständnis ist das Bundesverfassungsgericht nun zumindest in Bezug auf den BND abgerückt. Dessen Aufklärungsauftrag erschöpft sich nicht länger in der politischen Information; vielmehr könne dem BND als eigene Aufgabe auch die Früherkennung von aus dem Ausland drohenden Gefahren anvertraut werden, wenn diese eine „hinreichend internationale Dimension“ aufwiesen. ${ }^{94}$ Hiermit trägt das Gericht einer Veränderung der Bedrohungslagen und einem korrespondierenden Wandel ${ }^{95}$ des nachrichtendienstlichen Aufgabengebiets Rechnung: Zu denken sei etwa an Gefahren durch staatenübergreifend machtvoll agierende Netzwerke der organisierten Kriminalität, durch von außen gesteuerte Cyberangriffe auf wichtige Infrastrukturen oder durch Terrorakte, die sich als Ausdruck international verflochtener Konfliktlagen darstellten. Zwar könne der Bund den BND im Kontext der Auslandsaufklärung nicht allgemein zum Zweck der Gewährleistung der inneren Sicherheit betrauen. Die Gesetzgebungsbefugnis aus Art. 73 Abs. 1 Nr. 1 GG beschränke sich jedoch nicht auf die reduzierte Aufgabenzuweisung des BND, die Bundesregierung mit Entscheidungsgrundlagen zur Sicherung ihrer außen- oder verteidigungspolitischen Handlungsfähigkeit zu versorgen. In der

87 BVerfGE 133, 277, Rn. 119.

88 BVerfGE 133, 277, Rn. 118.

89 Dietrich (Fn. 3), Kap. III § 3 Rn. 5; Gärditz (Fn. 26), 8 f.

90 Vgl. Gazeas, Übermittlung nachrichtendienstlicher Erkenntnisse an Strafverfolgungsbehörden, 2014.

91 Götz, Innere Sicherheit, in: Isensee/Kirchhof (Hrsg.), HStR, Bd. 4, 3. Aufl. 2006, § 85 Rn. 40.

92 Näher zu den informationellen Kooperationsformen Thiel, Die „Entgrenzung“ der Gefahrenabwehr, 2011, S. 390 ff.; zum Trennungsgebot näher bei Fn. 155.

93 Dietrich (Fn. 3), Kap. III § 3 Rn. 5.

94 BVerfGE 154, 152, Rn. 128.

$95 \mathrm{Zu}$ diesem Wandel schon Wolff (Fn. 23), 1078. 
politischen Information liegt folglich zwar noch die primäre, aber nicht mehr die einzige Aufgabe der nachrichtendienstlichen Auslandsaufklärung. ${ }^{96}$

\section{Nachrichtendienste als Sicherheitsbehörden}

Mit der Anerkennung einer eigenständigen sicherheitsrechtlichen Aufgabe geht eine administrative Emanzipation einher: Die Stellung der Behörden des geheimdienstlichen Staats- und Verfassungsschutzes im System der Gefahrenabwehr war lange Zeit ungesichert. Sie oszillierte zwischen einer Zuordnung zur Polizei im formellen oder materiellen Sinne ${ }^{97}$ sowie der Zufluchtnahme in einer prekären Sonderrolle. ${ }^{98}$ Nach der Rechtsprechung des Bundesverfassungsgerichts ist der BND nicht auf die Rolle als Informationsdienstleister reduziert, sondern wird auch als Sicherheitsbehörde im Gefüge vernetzter Sicherheitsakteure konturiert. ${ }^{99}$ In den Tatbeständen der mit Wirkung zum 1. Januar 2022 neugefassten Befugnisnormen des BNDG spiegelt sich diese dualistische Konzeption des Aufklärungsauftrags deutlich wider (vgl. §§ 19 Abs. 1, 20 Abs. 1, 29 Abs. 1 bis 7, 30 Abs. 1 bis 5, 34 Abs. 1, 38 Abs. 1, 39 Abs. 1 bis 4 BNDG-neu). ${ }^{100}$

Die im BNDG-Urteil zunächst für den Auslandsnachrichtendienst entfaltete Doppelfunktionalität im Aufklärungsauftrag hat das Bundesverfassungsgericht im Antiterrordateibeschluss vom 10 . November 2020 verallgemeinert und auf sämtliche Nachrichtendienste erstreckt. Generell dienten die Nachrichtendienste in erster Linie der Information der politischen Entscheidungsträger, könnten daneben aber auch die Aufgabe der sicherheitsrechtlich relevanten Vorfeldaufklärung wahrnehmen. ${ }^{101}$ Dadurch möge sich zwar der Abstand zwischen Nachrichtendiensten und Polizeibehörden weiter verringern - eine Problematik, die je nach Perspektive mit „Vernachrichtendienstlichung der Polizei“ bzw. „Verpolizeilichung der Nachrichtendienste“ adressiert wird. ${ }^{102}$ Dies ändere jedoch nichts daran, „dass den Nachrichtendiensten für die Ge-

96 BVerfGE 154, 152, Rn. 128.

97 Formell Drews/Wacke/Vogel u.a., Gefahrenabwehr, 9. Aufl. 1986, § 5, S. 82: „polizeiliche Dienststelle“; materiell Thiel, Polizei- und Ordnungsrecht, 4. Aufl. 2020, § 3 Rn. 7: „dem präventivpolizeilichen Bereich der Gefahrenbekämpfung zuzuordnen“.

98 Gusy, Polizei- und Ordnungsrecht, 10. Aufl. 2017, Rn. 37; Würtenberger/Heckmann/ Tanneberger, Polizeirecht in Baden-Württemberg, 7. Aufl. 2017, § 3 Rn. 22; Kingreen/ Poscher, Polizei- und Ordnungsrecht, 11. Aufl. 2020, § 2 Rn. 17.

99 Dietrich (Fn. 12), 175; eingehend Unterreitmeier (Fn. 6), $177 \mathrm{ff}$.

100 Vgl. auch Dietrich (Fn. 35), Ausschuss-Drs. 19(4)731 G, S. 9: ,zieht sich wie ein roter Faden durch die Novelle“.

101 BVerfGE 156, 11 Rn. 103 f. - Antiterrordateigesetz II.

102 Bäcker (Fn. 65), § 28 Rn. 33 ff.; dazu ferner Schafranek, Die Kompetenzverteilung zwischen Polizei und Verfassungsschutzbehörden in der Bundesrepublik Deutschland, 2000, S. 150 ff.; Würtenberger, Polizei- und Sicherheitsrecht vor den Herausforderungen des Terrorismus, in: Masing/Jouanjan (Hrsg.), Terrorismusbekämpfung, Menschenrechtsschutz und Föderation, 2008, S. 27 (35 f.); Mehde, Terrorismusbekämpfung durch Organisationsrecht, JZ 2005, 815 (817); Wolff, Die Grenzverschiebung von polizeilicher und nachrichtendienstlicher Sicherheitsgewährleistung, DÖV 2009, 597 ff.; Baldus, Entgrenzungen des Sicherheitsrechts, DV 47 (2014), 1 (4); Augsberg, Vernachrichtendienstlichung der Polizei?, Jahrbuch Öffentliche Sicherheit 2018/2019, 115 ff. 
fahrenfrüherkennung vergleichbar weitreichende Befugnisse zur Datensammlung zur Verfügung stehen wie bei der politischen Vorfeldaufklärung und dass sie im Gegenzug nicht operativ tätig werden". ${ }^{103}$ Soweit die Literatur die Erstreckung der politischen Primärfunktion auf sämtliche Nachrichtendienste im ATDG-II-Beschluss als überschießende induktive Verallgemeinerung kritisiert, trifft es zwar zu, dass diese für den BND ursprünglich aus der begrenzten Kompetenzgrundlage des Art. 73 Abs. 1 Nr. 1 GG hergeleitet wurde, während weder für den Verfassungsschutz noch für sein militärisches Pendant entsprechende Grenzen gelten (vgl. Art. 73 Abs. 1 Nr. 10 lit. b und c GG). ${ }^{104}$ Für den hier interessierenden Kontext bedeutet dies allerdings nur, dass BfV und MAD erst recht als Sicherheitsbehörden zu gelten haben.

\section{Dogmatisierung der nachrichtendienstlichen Befugnisse}

Die Leistungsfähigkeit der Nachrichtendienste hängt nicht nur von einer zeitgemäßen Ausgestaltung des Aufgabenprofils, sondern auch maßgeblich davon ob, dass sein Eingriffsinstrumentarium an sich rasant verändernde technische, politische und soziale Kontexte angepasst und grundrechtssensibel fortentwickelt wird. In diesem Punkt hat die jüngste Rechtsprechung des Bundesverfassungsgerichts ebenfalls für eine Fortschreibung der Dogmatik gesorgt. Sie lehnt sich zum einen an die zum Polizeirecht entwickelten Maßgaben an und setzt zum anderen eine ständige Rechtsprechung fort, im Rahmen derer die Nachrichtendienste grundsätzlich als Teil der Sicherheitsarchitektur angesehen und sie ebenso grundsätzlich den hierbei geltenden Rechtsbindungen (Art. 1 Abs. 3, 20 Abs. 3 GG) unterworfen werden. ${ }^{105}$ Wenngleich dem Narrativ der „Verrechtlichungsfalle“ 106 danach von vornherein der Boden entzogen und die Tätigkeit der Nachrichtendienste damit endgültig dem gubernativen Arkanbereich entrissen ist, verliert das Gericht die Besonderheiten des nachrichtendienstlichen Aufgaben- und Tätigkeitsspektrums nicht aus dem Blick.

\section{Konvergenz von Nachrichtendienst- und Polizeirecht}

\section{a) Konditional programmierte, anlassabhängige Tatbestände als Regelfall}

War die Rechtsprechung des Bundesverfassungsgerichts zu den Eingriffsschwellen der Überwachungsmaßnahmen im Nachrichtendienstrecht in der Vergangenheit deutlich weniger gefestigt als im Polizeirecht, ist diese Frage mittlerweile im Sinne einer

103 BVerfGE 156, 11 Rn. 104 - Antiterrordateigesetz II.

104 Unterreitmeier (Fn. 6), 179.

105 Stellvertretend Lischka/Graulich, Stand und Perspektiven der gesetzlichen Fortentwicklung der parlamentarischen Kontrolle der Nachrichtendienste, in: Dietrich/Gärditz/Graulich u.a. (Hrsg.), Nachrichtendienste im demokratischen Rechtsstaat, 2018, S. 55 (56 ff.); Gusy, Kontrolle der Nachrichtendienste, VerwArch 106 (2015), 437 (438).

$106 \mathrm{Zu}$ dem ,wohlfeilen Argument“, dass sich die Befugnisse eines auf Geheimhaltung und Flexibilität angewiesenen Nachrichtendienstes schon regelungstechnisch nicht normativ abbilden und eingrenzen ließen, vgl. Gärditz (Fn. 9), 470 f.; Wegener (Fn. 29), 320, m.w.N. 
weitgehenden dogmatischen Konvergen ${ }^{107}$ zwischen diesen beiden Teilbereichen des Sicherheitsrechts beantwortet. Analog zum Polizei- und Ordnungsrecht bedarf es hiernach auch im Recht der Nachrichtendienste regelmäßig konditional programmierter, an einen bestimmten Anlass geknüpfter Tatbestände, um nachrichtendienstliche Eingriffsbefugnisse verfassungsrechtlich rechtfertigen zu können. ${ }^{108}$ Besonders deutlich wird die Konvergenz von Polizei- und Nachrichtendienstrecht, wenn in näher bestimmten Fällen für Übermittlungen aus nachrichtendienstlichen Erkenntnissen sogar das Vorliegen einer unmittelbar bevorstehenden Gefahr für ein hochrangiges Rechtsgut gefordert wird. ${ }^{109}$

Wird der Abstand zwischen dem gesetzlichen Auftrag von Polizeibehörden und Nachrichtendiensten geringer, erscheint es nur logisch und sachgerecht, dass sich auch die materiellrechtlichen Anforderungen hinsichtlich der von Verfassungs wegen einzuziehenden und tatbestandlich abzubildenden Eingriffsschwellen einander annähern. Die Rechtsprechung zum BKAG hat gerade auf die „Vernachrichtendienstlichung" des Polizeirechts reagiert und dieser insofern Grenzen gesetzt, als sie eine wenigstens hinreichend konkretisierte Gefahr in dem Sinne verlangte, dass zumindest tatsächliche Anhaltspunkte für die Entstehung einer konkreten Gefahr vorliegen. ${ }^{110}$ Insofern lag es nahe, diese Maßstäbe auf das Nachrichtendienstrecht zu übertragen. ${ }^{111}$ Dies hat das Bundesverfassungsgericht in den Beschlüssen zur Bestandsdatenauskunft sowie zum Antiterrordateigesetz getan: Danach gelten die verfassungsrechtlichen Anforderungen grundsätzlich ,für alle Eingriffsermächtigungen mit präventiver Zielrichtung, also auch für die [...] Nachrichtendienste“. ${ }^{112}$ Diese gleichläufige Maßstabsbildung für die Überwachungsbefugnisse von Polizei und Nachrichtendiensten wirft die Frage nach Bedeutung und Inhalt eines nachrichtendienstlichen Gefahrenund Verursachungsbegriffs sowie der Abgrenzung zu seinem jeweiligen polizeirechtlichen Pendant auf.

\section{aa) Nachrichtendienstlicher Gefahrbegriff}

Nachrichtendienstliche Überwachungsmaßnahmen werden nach der Rechtsprechung des Bundesverfassungsgerichts an "tatsächliche Anhaltspunkte“ rückgebunden. ${ }^{113}$ Was damit gemeint ist, bleibt in den Entscheidungen relativ vage und bedarf ausgehend vom gesetzlichen Handlungsauftrag der Nachrichtendienste als Frühwarnsysteme einer Konkretisierung mit Blick auf die Eingriffsschwelle und den Rechtsgüterschutz.

107 Vgl. Bäcker, in: Lisken/Denninger, Handbuch des Polizeirechts, 6. Aufl. 2018, Kap. B. Rn. 249; der „Konvergenzthese“ prinzipiell ablehnend gegenüberstehend Lindner/Unterreitmeier (Fn. 30), $172 \mathrm{f}$.

108 Allgemein hierzu Pfefferl, Die Dichotomie konditionaler und finaler Normen, 2014; Breuer, Konditionale und finale Rechtsetzung, AöR 127 (2002), 523 (525 ff.).

109 BVerfGE 154, 152, Rn. 174, 228. Dazu noch unten 2.

110 BVerfGE 141, 220, Rn. $111 \mathrm{f}$.

111 Bäcker (Fn. 65), § 28 Rn. 108, m.w.N.

112 BVerfGE 155, 119, Rn. 151 - Bestandsdatenauskunft II; BVerfGE 156, 11 Rn. 119 - Antiterrordateigesetz II; andeutungsweise bereits BVerfGE 154, 152, Rn. 222 - BNDG-Urteil.

113 BVerfGE 155, 119, Rn. 151; 156, 11 Rn. 119. 


\section{(1) Eingriffsschwelle}

Hergebrachte und systemprägende Eingriffsschwelle im Polizei- und Ordnungsrecht ist die im Einzelfall bestehende, konkrete Gefahr. ${ }^{114}$ Eine solche Gefahr kann im Recht der Nachrichtendienste von vornherein nicht verlangt sein: Würde man den nachrichtendienstlichen mit dem polizeilichen Gefahrenbegriff gleichsetzen und für die Tätigkeit der Nachrichtendienste, die nach den gesetzlichen Auftragszuweisungen $^{115}$ im Vorfeld konkretisierter polizeilicher Gefahrenlagen ansetzt, ${ }^{116}$ stets das Vorliegen einer in diesem Sinne konkretisierten Bedrohung eines Schutzguts verlangen, hätte dies zwangsläufig die Handlungsunfähigkeit der Dienste zur Folge. ${ }^{117}$ Allerdings ist selbst die Polizei bei ihrer informationsbezogenen, das Gefahrenvorfeld aufklärenden Arbeit nicht an die klassischen Schwellen Gefahr und Störer gebunden, weil diese dort, wo es weder eine Gefahr noch deren Verursacher geben kann, naturgemäß keine Aussagekraft besitzen. ${ }^{118}$ Da das Gefahrenvorfeld ureigenes Hoheitsgebiet der Nachrichtendienste ist, ${ }^{119}$ gilt dies umso mehr für ihren Aufklärungsauftrag. Dieser kann - in den Worten des Bundesverfassungsgerichts - „bereits weit im Vorfeld von konkreten Gefahren" 120 ansetzen. Entsprechend werden von dem nachrichtendienstlichen Gefahrenbegriff des $\S 19$ Abs. 4 BNDG-neu - über den polizeilichen Gefahrenbegriff hinaus - gerade auch Entwicklungen im Ausland erfasst, die sich negativ auf die Stellung der Bundesrepublik Deutschland in der Staatengemeinschaft auswirken können, ohne dass dies bereits konkret absehbar oder hinreichend wahrscheinlich sein müsste. Als Beispiele nennt die Gesetzesbegründung die Zuspitzung einer politischen Krise in der Peripherie Europas oder das Aufflammen bewaffneter Konflikte zwischen den Anrainerstaaten einer wichtigen maritimen Handelsroute. Polizeirechtlich gesprochen ist der nachrichtendienstliche Gefahrenbegriff somit ein Gefahrenvorfeldbegriff. ${ }^{121}$

Im Rahmen der gezielten Erfassung der Telekommunikation von deutschen Staatsangehörigen, die aufgrund des Umstands, dass jene in deutlich weitergehendem Umfang dem Zugriff deutscher Behörden unterliegen und damit leichter Folgemaßnahmen ausgesetzt sind, ein größeres Eingriffsgewicht als gegenüber sich im Ausland befindenden Ausländern aufweise, hat das Bundesverfassungsgericht die Eingriffsschwelle unter erneuter Bezugnahme auf seine Maßstäbe im BKAG-Urteil fortge-

114 Vgl. die Legaldefinitionen des polizeirechtlichen Gefahrbegriffs: § 2 Nr. 1 NdsPOG; § 4 Nr. 3 lit. a SächsPVDG; $\S 3$ Nr. 3 lit. a SOG LSA; 54 Nr. 3 lit. a ThürOBG.

115 Siehe oben Fn. 83.

116 Bäcker (Fn. 65), § 28 Rn. 106: „Herkömmlich [...] weiter im Vorfeld sozialer Konflikte verortet als die der Polizei“.

117 Lindner/Unterreitmeier (Fn. 30), 171; differenzierend Bäcker, Zur Reform der Eingriffstatbestände im Nachrichtendienstrecht, in: Dietrich/Gärditz/Graulich u.a. (Hrsg.), Nachrichtendienste im demokratischen Rechtsstaat, 2018, S. 137 (142, 147).

118 OVG Hamburg, NVwZ-RR 2009, 878 (882); Möstl, Die staatliche Garantie für die öffentliche Sicherheit und Ordnung, 2002, S. 210 f.; ders., Die neue dogmatische Gestalt des Polizeirechts, DVB1. 2007, 581 (585 f.); Trute, Gefahr und Prävention in der Rechtsprechung zum Polizei- und Ordnungsrecht, DV 36 (2003), 501 (502).

119 Allerdings bereits von einem Wechsel der „Führungsrolle“ von den Nachrichtendiensten zur Polizei ausgehend Wolff (Fn. 102), 600.

120 BVerfGE 154, 152, Rn. 218.

121 BT-Drs. 19/26103, S. 57. 
schrieben. ${ }^{122}$ Eine hinreichend konkretisierte Gefahr in diesem Sinne kann nach dem verfassungsgerichtlichen Stufenmodell ${ }^{123}$ bereits dann bestehen, wenn sich der zum Schaden führende Kausalverlauf noch nicht mit hinreichender Wahrscheinlichkeit vorhersehen lässt, sofern bereits bestimmte Tatsachen auf eine im Einzelfall drohende Gefahr für ein überragend wichtiges Rechtsgut hinweisen. Die Tatsachen müssen dafür zum einen den Schluss auf ein wenigstens seiner Art nach konkretisiertes und zeitlich absehbares Geschehen zulassen, zum anderen darauf, dass bestimmte Personen beteiligt sein werden, über deren Identität zumindest so viel bekannt ist, dass die Überwachungsmaßnahme gezielt gegen sie eingesetzt und weitgehend auf sie beschränkt werden kann („lagebezogener Gefahrenverdacht"). Darüber hinaus können Überwachungsmaßnahmen auch dann erlaubt werden, wenn zwar noch nicht ein seiner Art nach konkretisiertes und zeitlich absehbares Geschehen erkennbar ist, jedoch das individuelle Verhalten einer Person die konkrete Wahrscheinlichkeit begründet, dass sie solche Straftaten in überschaubarer Zukunft begehen wird (,,personenbezogener Gefahrenverdacht"). ${ }^{124}$

Eine nähere Konkretisierung dieser Kriterien steht noch aus: Hatte das Bundesverfassungsgericht im BNDG-Urteil noch weithin offengelassen, wie diese Maßgaben in das Recht der Nachrichtendienste zu übersetzen sind, hat es in seinem Beschluss zur Bestandsdatenauskunft immerhin klargestellt, dass es ausreicht, wenn eine nachrichtendienstliche Überwachungsmaßnahme ,,zur Aufklärung einer bestimmten, nachrichtendienstlich beobachtungsbedürftigen Aktion oder Gruppierung im Einzelfall geboten ist ${ }^{\prime} .{ }^{125}$ Für den nachrichtendienstlichen Gefahrbegriff als Tatsachenbasis erforderlich, aber auch ausreichend sind konkrete und hinreichend verdichtete Umstände. ${ }^{126}$ Danach reichen bloße Vermutungen, Spekulationen oder Hypothesen, die sich nicht auf beobachtbare Fakten stützen können, nicht aus. Umgekehrt bedarf es keiner bestimmten Indizien für eine drohende Gefahr im polizeirechtlichen Sinne oder konkreter Verdachtsmomente für eine Straftat. ${ }^{127}$

\section{(2) Rechtsgüterschutz}

Nach der sicherheitsverfassungsrechtlichen Schablone, die das Bundesverfassungsgericht seit dem BKAG-Urteil ${ }^{128}$ bei seiner Kontrolle sicherheitsbehördlicher Überwachungsmaßnahmen anlegt, stehen eigentlich die Parameter „Eingriffsschwelle“ und „Rechtsgüterschutz“ in einem partiellen wechselseitigen Kompensationsverhältnis zu-

122 BVerfGE 154, 152, Rn. 186.

123 Zu diesem Bäcker (Fn. 65), § 28 Rn. 94 ff.

124 BVerfGE 141, 220, Rn. 112.

125 BVerfGE 155, 119, Rn. 151, annähernd gleichlautend auch Rn. 157, 218, 269.

126 Für die strategische Telekommunikationsüberwachung BVerfGE 100, 313 (395); für die Beobachtung einer Einzelperson durch den Verfassungsschutz BVerwG, BeckRS 2020, 43572, Rn. 23.

127 BVerfGE 120, 274 (330); Gusy, Organisation und Aufbau der deutschen Nachrichtendienste, in: Dietrich/Eiffler (Hrsg.), Handbuch des Rechts der Nachrichtendienste, 2017, Kap. IV § 1 Rn. 11.

128 BVerfGE 141, 220, Rn. $109 \mathrm{ff}$. 
einander. ${ }^{129}$ Das bedeutet: Je niedriger die Eingriffsschwellen ausfallen, umso höhere Anforderungen sind grundsätzlich an das geschützte Rechtsgut zu stellen und umgekehrt. ${ }^{130}$ Mit Blick auf den Rechtsgüterschutz ist jedoch im Recht der Nachrichtendienste die Besonderheit zu beachten, dass ihr Aufgabenbereich regelmäßig von vornherein durch den Schutz „besonders gewichtiger Rechtsgüter“" gekennzeichnet ist. ${ }^{131}$ Wo dies vereinzelt nicht der Fall ist (z.B. bei $\S 9$ Abs. 1 Satz 1 Nr. 1 BVerfSchG), ${ }^{132}$ werden die Eingriffsermächtigungen den verfassungsrechtlichen Anforderungen offensichtlich nicht gerecht. Wo dies hingegen der Fall ist, versprechen weitere Qualifizierungen jedoch ebenso offensichtlich keinen rechtsstaatlichen Zugewinn. Kompensationsbedarf auf Seiten der Eingriffsschwellen ist im Recht der Nachrichtendienste vielmehr - ausnahmsweise ${ }^{133}$ - durch verfahrensrechtliche Sicherungen aufzulösen. ${ }^{134}$

Die Voraussetzungen für eine Aufklärungsmaßnahme zur Früherkennung von aus dem Ausland drohenden Gefahren von internationaler Bedeutung werden mittlerweile in $\S 19$ Abs. 4 BNDG-neu konkretisiert. Danach definiert sich der nachrichtendienstliche Gefahrenbegriff durch das Vorliegen tatsächlicher Anhaltspunkte für einen möglichen Erkenntnisgewinn mit Bezug zu einem näher bestimmten Gefahrenbereich (Landes- oder Bündnisverteidigung, Auslandseinsätze der Bundeswehr, Terrorismus oder Extremismus, u.s.w.) oder zum Schutz näher bezeichneter bedeutsamer Rechtsgüter (z.B. Leib, Leben oder Freiheit einer Person; Bestand oder Sicherheit des Bundes oder eines Landes; außenpolitische Handlungsfähigkeit der Bundesrepublik). Während die Gesetzesbegründung ${ }^{135}$ von einem Alternativverhältnis zwischen Gefahrenbereich und zu schützendem Rechtsgut ausgeht und das Gesetz selbst in diesem Punkt eine klare Aussage vermissen lässt - wie sich die Nummern 1 und 2 des $\S 19$ Abs. 4 BND-neu zueinander verhalten, wird tatbestandlich nicht angeleitet -, hat das Bundesverfassungsgericht in seiner Rechtsprechung Gefahrenlage und Rechtsgut stets kumulativ vorausgesetzt und - wie soeben dargelegt wurde - den im Nachrichtendienstrecht von vornherein hochrangigen Rechtsgüterschutz als fixen Parameter der Eingriffsermächtigungen betont. ${ }^{136}$ Daneben vermag das Konstrukt einer „Gefahr für einen Gefahrenbereich" weder grammatikalisch noch rechtssystematisch zu überzeu-

129 Bäcker (Fn. 65), § 28 Rn. 103; ders., Schriftliche Stellungnahme an den Innenausschuss v. 2.11.2020, Ausschuss-Drs. 19(4)627 B, S. 5.

130 BVerfGE 155, 119, Rn. 147 - Bestandsdatenauskunft II.

131 BVerfGE 155, 119, Rn. 151.

132 Die Regelung ermächtigt zu Überwachungsmaßnahmen mit hoher Eingriffsintensität wie Bild- und Tonaufzeichnungen außerhalb von Wohnungen, langfristigen Observationen oder den gezielt gegen bestimmte Personen gerichteten Einsatz von Vertrauensleuten und Gewährspersonen, ohne qualifizierende Anforderungen an den Rechtsgüterschutz zu stellen.

133 Die vom Bundesverfassungsgericht für das Sicherheitsrecht entwickelten prozeduralen Sicherungen können materielle Schwächen der Eingriffsermächtigungen grundsätzlich nicht ausgleichen, sondern allenfalls die materiellen Anforderungen ergänzen, um spezifische Risiken von Überwachungsmaßnahmen rechtsstaatlich einzuhegen. Das Recht der Nachrichtendienste bildet hier insofern eine Ausnahme, vgl. Bäcker (Fn. 65), § 28 Rn. 84.

134 Siehe unten 2.

135 BT-Drs. 19/26103, S. 57.

136 Darauf ebenfalls hinweisend Dietrich (Fn. 35), Ausschuss-Drs. 19(4)731 G, S. 24. 
gen. ${ }^{137}$ Beides sollte in der Anwendungspraxis des $\S 19$ Abs. 4 BNDG-neu berücksichtigt werden, solange der Gesetzgeber nicht normativ nachsteuert.

\section{bb) Nachrichtendienstlicher Verursacherbegriff}

Da die nachrichtendienstliche Tätigkeit im Vorfeld einer konkreten Gefahr ansetzt, lassen sich auch die Maßgaben polizeirechtlicher Pflichtigkeit nicht unbesehen in das Recht der Nachrichtendienste übertragen. Wo es noch keine konkrete Gefahr gibt, kann auch niemand kraft Verhaltens oder tatsächlicher Sachherrschaft für ihre Entstehung verantwortlich gemacht werden. ${ }^{138}$ Gleichwohl ist das rechtsstaatliche Bedürfnis, die Zielpersonen individualbezogener Überwachungsmaßnahmen der Nachrichtendienste dogmatisch zu erfassen und im Rahmen eines „nachrichtendienstlichen Störerbegriffs"139 normenklar gesetzlich auszuformen, verfassungsrechtlich evident. ${ }^{140}$ Der Kreis der Betroffenen eingriffsintensiver nachrichtendienstlicher Informationseingriffe kann nicht beliebig weit gezogen werden. Gegenüber Personen, die als mögliche Verursacher von Gefahren mit Blick auf ihnen gegenüber zu ergreifenden Folgemaßnahmen im unmittelbaren Interesse der Nachrichtendienste stehen, hat die Überwachung eine besondere Intensität und es besteht eine gesteigerte Wahrscheinlichkeit von belastenden (operativen, aktionellen und imperativen) Folgenwirkungen. ${ }^{141}$ Bei weniger eingriffsintensiven Überwachungsmaßnahmen bedarf es hingegen keiner flankierenden Adressatenregelungen. ${ }^{142}$

Gesetzliche Bestimmungen über den Adressaten sicherheitsrechtlicher Maßnahmen sind prinzipiell keine bloßen Verfahrens- oder Ordnungsvorschriften. ${ }^{143}$ Vielmehr erfüllen sie in Ansehung der behördlichen Eingriffsbefugnisse eine unverzichtbare Komplementärfunktion, indem sie erst im Zusammenspiel mit ihnen zu Eingriffen in die Rechtspositionen der Betroffenen ermächtigen. ${ }^{144}$ Adressatenregelungen ermöglichen nicht nur staatliche Freiheitseingriffe, sondern begrenzen diese zugleich. Bei ihnen handelt es sich um eine bereichsspezifische Typisierung des verfassungsrechtlichen Grundsatzes der Verhältnismäßigkeit, dem gerade im Vorfeld konkretisierter Gefährdungslagen Rechnung zu tragen ist. Aus dem Verhältnismäßigkeitsgrundsatz hat das Bundesverfassungsgericht im BKAG-Urteil gestufte Anforderungen für Überwachungsmaßnahmen gegenüber Personen hergeleitet, die nicht bereits als Handlungsoder Zustandsverantwortliche im polizeirechtlichen Sinne bzw. als strafprozessual

137 Vgl. schon Bäcker (Fn. 117), S. 142.

138 Deutlich W.-R. Schenke/R. P. Schenke, Polizei- und Ordnungsrecht, in: Steiner/Brinktrine (Hrsg.), Besonderes Verwaltungsrecht, 9. Aufl. 2018, § 2 Rn. 231; zur Ambivalenz der Maßnahmeadressaten im Gefahrenvorfeld $\mathrm{Kral}$, Die polizeilichen Vorfeldbefugnisse als Herausforderung für Dogmatik und Gesetzgebung des Polizeirechts, 2012, S. 149 ff.; mit einem Plädoyer für eine analoge Anwendung der Störervorgaben im Gefahrenvorfeld Möstl, Polizeibefugnisse bei drohender Gefahr, BayVBl. 2018, 156 (163).

139 Vgl. insoweit schon Lindner/Unterreitmeier (Fn. 30), 173.

140 BVerfGE 141, 220, Rn. $114 \mathrm{ff}$.

141 BVerfGE 154, 152, Rn. 188; daran anschließend BT-Drs. 18/9041, S. 75.

142 BVerfGE 155, 119, Rn. 146 ff. - Bestandsdatenauskunft II.

143 Beckermann, Verantwortlichkeitsnormen als „Allgemeines Ordnungsrecht“, DÖV 2020, 144 (146).

144 Pointiert Kingreen/Poscher (Fn. 98), § 9 Rn. 3. 
Tatverdächtige in die Verantwortung genommen werden können. ${ }^{145}$ Diese Maßgaben hat es im BNDG-Urteil auf das Recht der Nachrichtendienste übertragen: Danach hat der Gesetzgeber als Grundlage einer zielgerichteten Strukturierung des Überwachungsprozesses die möglichen Gründe und Gesichtspunkte, unter denen nachrichtendienstliche Überwachungsmaßnahmen gezielt auf bestimmte Personen gerichtet werden dürfen, festzulegen. ${ }^{146}$ So kann er etwa die Überwachung von Personen vorsehen, die als mögliche Verursacher von Gefahren, als Nachrichtenmittler oder als sonst näher qualifizierte Informanten in Betracht kommen und hierbei möglicherweise Präferenzregeln aufstellen, nach denen etwa die zielgerichtete Überwachung von völlig unbeteiligten Personen nur nachrangig zulässig ist.

Für den notwendigen Verursachungszusammenhang im Vorfeldbereich reicht es dabei aus, dass tatsächliche Anhaltspunkte für die Involvierung einer Person in ein tatsächliches Geschehen bestehen, von dem auf das Vorhandensein oder die Potenzialität einer Gefährdung für die nachrichtendienstlichen Schutzgüter geschlossen werden kann. ${ }^{147}$ Der Adressat einer nachrichtendienstlichen Überwachungsmaßnahme muss aus Sicht eines verständigen Dritten den objektiven Umständen nach selbst in die Gefährdungssituation „verfangen“ sein. ${ }^{148}$ Dem trägt der Gesetzgeber mittlerweile mit einem neu eingefügten Begriff des „Verursachers“ einer nachrichtendienstlichen Gefahr Rechnung. ${ }^{149}$ Bei Dritten als Adressaten von Überwachungsmaßnahmen genügt es demgegenüber, wenn bei ihnen eine ,spezifische individuelle Nähe“ zu der aufzuklärenden Situation besteht. ${ }^{150}$ Insoweit müsse der Normgeber allerdings nicht das Vorliegen objektivierter Eingriffsschwellen verlangen, sondern könne sich mit einer spezifizierenden Benennung der Zwecke, derentwegen Personen gezielt überwacht werden dürfen, und damit nur mit finalen Maßgaben begnügen. ${ }^{151}$

\section{b) Final angeleitete, anlasslose Befugnisse im Ausnahmefall}

Die aufgezeigte „Deprivilegierung der Geheimdienste“152 hinsichtlich der Eingriffsschwellen trägt nur insoweit, als nachrichtendienstliche Überwachungsmaßnahmen tatsächlich mit präventiv-polizeilichen Maßnahmen vergleichbar sind. Wo dies nicht der Fall ist, begründet der besondere Aufgaben- und Befugniskreis der Nachrichtendienste, der sich gerade durch das Fehlen operativer Handlungsermächtigungen auszeichnet (vgl. § 8 Abs. 3 BVerfSchG, § 2 Abs. 3 BNDG, § 4 Abs. 2 MADG), nach wie vor ein „verfassungsrechtliches Privileg““. ${ }^{153}$ Nach diesem darf der Gesetzgeber den Nachrichtendiensten Ermittlungen und Überwachungen unter geringeren Voraussetzungen erlauben als anderen, mit operativen und imperativen Befugnissen ausgestat-

145 BVerfGE 141, 220, Rn. 114.

146 BVerfGE 154, 152, Rn. 187.

147 So Lindner/Unterreitmeier (Fn. 30), 173, mit der Begriffsschöpfung der ,involvierten Person".

148 BVerfGE 141, 220, Rn. 109.

149 Vgl. $\S \S 20$ Abs. 2 Nr. 1, 34 Abs. 5 Nr. 1, 2 BNDG-neu.

150 BVerfGE 141, 220, Rn. 116.

151 BVerfGE 154, 152, Rn. 187.

152 Wegener (Fn. 29), 312 ff.

153 Bäcker (Fn. 107), Kap. B. Rn. 249. 
teten Behörden. Verfügt eine Behörde kumulativ über informationelle und operativpolizeiliche Eingriffsbefugnisse (wie z.B. das BKA), gewinnt die Informationserhebung eine höhere Eingriffsintensität. Das Gefährdungspotential der Überwachung für die grundrechtlich geschützte Freiheitssphäre des Betroffenen liegt höher, wenn dieselbe Behörde ohne weitere Verfahrensschritte unmittelbar Folgeeingriffe vornehmen darf, die ggf. mittels unmittelbarem Zwang auch gegen den Willen des Betroffenen durchgesetzt werden können (Durchsuchung, Beschlagnahme, Ingewahrsamnahme etc.). ${ }^{154}$ Dies ist bei den Nachrichtendiensten aufgrund des ursprünglich vorkonstitutionellen, auf das Memorandum der Alliierten Militärgouverneure zum Grundgesetz vom 14. April 1949 („Polizei-Brief“) ${ }^{155}$ zurückgeführten Trennungsgebotes, ${ }^{156}$ das von der Rechtsprechung in die Verfassungen von Bund und Ländern ,inkorporiert“ wurde, ${ }^{157}$ prinzipiell ausgeschlossen.

Der Sache nach, wenngleich nicht explizit, hat das Bundesverfassungsgericht ein „verfassungsrechtliches Privileg“ im Fall der Ausland-Ausland-Fernmeldeaufklärung anerkannt. Im Ausgangspunkt betont der Senat zwar, dass es sich bei der strategischen Telekommunikationsüberwachung - auch im Verhältnis zur Überwachung individueller Telekommunikation - aufgrund ihrer außerordentlichen Streubreite um ein Instrument von besonders schwerem Eingriffsgewicht handelt. ${ }^{158}$ Dies hätte bei konsequenter Handhabung der Konvergenzthese, welche die verfassungsrechtliche Privilegierung gerade mit der regelhaft verminderten Eingriffsintensität nachrichtendienstlicher im Verhältnis zu polizeilichen Überwachungsbefugnisse begründet, ${ }^{159}$ eigentlich zur Anwendung der restriktiven Maßgaben aus dem Polizeirecht führen müssen. Der Umstand, dass die strategische Aufklärung durch eine Behörde vorgenommen wird, die selbst grundsätzlich über keine operativen Befugnisse verfügt, senkt nach Auffassung des Bundesverfassungsgerichts die Eingriffsintensität nicht auf ein verfassungsrechtliches Minimum ab, sondern führt lediglich dazu, dass die Eingriffsfolgen

154 Bäcker (Fn. 107), Kap. B. Rn. 249; Gärditz (Fn. 26), 12; Lindner/Unterreitmeier (Fn. 30), 170.

155 Abgedruckt bei Feldkamp, Die Beziehungen des Parlamentarischen Rates zu den Militärregierungen, 1995, S. 231: „2. The federal government will also be permitted to establish an agency to collect and disseminate information concerning subversive activities directed against the federal government. This agency shall have no police authority“.

156 Bäcker (Fn. 107), Kap. B. Rn. 244 ff.; Dorn, Das Trennungsgebot in verfassungshistorischer Perspektive, 2004; Urban, Das Trennungsgebot als Prinzip, 2021, S. 89 ff. et passim; Denninger, Die Trennung von Verfassungsschutz und Polizei und das Grundrecht auf informationelle Selbstbestimmung, ZRP 1981, 231 ff.; ders., Verfassungsschutz, Polizei und die Bekämpfung der Organisierten Kriminalität, KritV 77 (1994), 232 (235ff.); Gusy, Polizei und Nachrichtendienste im Kampf gegen die Organisierte Kriminalität, KritV 77 (1994), 242 ff.; demgegenüber das bisherige Verständnis des Trennungsgebotes nicht für ausreichend haltend und für ein „neues“ Gebot der Trennung werbend Rusteberg, Informationsherrschaft durch Polizei und Nachrichtendienste, in: Kulick/Goldhammer (Hrsg.), Der Terrorist als Feind?, 2020, S. 215 (233 ff.); zustimmend Gusy (Fn. 15), 145.

157 Grundlegend BVerfGE 133, 277, Rn. 115 ff. - Antiterrordatei. Mit Blick auf Art. 83 Abs. 3 Satz 1 SächsVerf („Der Freistaat unterhält keinen Geheimdienst mit polizeilichen Befugnissen“) und die Erfahrungen mit der Staatssicherheit der DDR etwa SächsVerfGH, NVwZ 2005, 1310 (1311).

158 BVerfGE 154, 152, Rn. 146.

159 Bäcker (Fn. 107), Kap. B. Rn. 249. 
„etwas abgemildert“ werden. ${ }^{160}$ Dass im Fall der strategischen Überwachung der ausländischen Telekommunikation gleichwohl auf näher konkretisierte Eingriffsschwellen verzichtet werden kann - was einem „,verfassungsrechtlichen Privileg“ entspricht -, begründet das Gericht zum einen mit dem überragenden öffentlichen Interesse an einer wirksamen Auslandsaufklärung, ${ }^{161}$ zum anderen mit den bei dieser bestehenden besonderen Erkenntnisproblemen. ${ }^{162}$ Die Auslandsaufklärung betreffe Vorgänge in anderen Ländern, in denen der deutsche Staat allenfalls punktuell mit eigenen Erkenntnisquellen präsent sei und in denen er nicht über Hoheitsbefugnisse verfüge, die ihm einen unmittelbaren Zugriff auf Informationen ermöglichten. Dabei müsse die Aufklärung im Interesse der Handlungsfähigkeit und Sicherheit der Bundesrepublik insbesondere auch an Informationen gelangen können, die ihr - möglicherweise in nachteiliger Absicht - gezielt vorenthalten und in der Hoheitssphäre des Drittstaats geheim gehalten werden. Die Maßnahmen der Aufklärung könnten zudem nach dem Recht des Zielstaats nicht selten illegal, jedenfalls oft unerwünscht sein. Dabei sei der Dienst zugleich mit den Abwehrtätigkeiten der Zielländer konfrontiert, die die Aufklärung ihrerseits mit polizeilichen und nachrichtendienstlichen Mitteln behinderten und zu hintertreiben suchten. „Die Arbeit ist damit besonders gefährdet und prekär und auf außergewöhnliche Mittel verwiesen“. 163

Eine anlasslose, im Wesentlichen allein final angeleitete und begrenzte Befugnis bleibt auch im Recht der Nachrichtendienste eine „Ausnahmebefugnis“. ${ }^{164}$ Im Rahmen zunehmend dynamischer Szenarien einer globalisierten Sicherheitslage stellt die anlasslose strategische Telekommunikationsaufklärung die „Kaltstartfähigkeit“"165 des BND sicher, um bei volatilen Lagen der Bundesregierung kurzfristig die benötigten Informationen zur Verfügung stellen zu können. Die strategische Ausland-Fernmeldeaufklärung wird deshalb berechtigterweise „zum unverzichtbaren Methodenspektrum für eine erfolgreiche Aufgabenerfüllung des Bundesnachrichtendienstes" 166 gerechnet. Die nicht an einen konkreten Anlassfall geknüpfte, eingriffsintensive Ausnahmebefugnis lässt sich allerdings nur dadurch legitimieren, dass sie von einer Behörde wahrgenommen wird, die selbst grundsätzlich keine operativen Befugnisse zur Gefahrenabwehr hat; als Ausnahmeermächtigung bedarf sie zu ihrer verfassungsrechtlichen Rechtfertigung zudem weiterer verfahrensrechtlicher Sicherungen. ${ }^{167}$

160 BVerfGE 154, 152, Rn. 165.

161 BVerfGE 154, 152, Rn. $161 \mathrm{ff}$.

162 BVerfGE 154, 152, Rn. 159.

163 BVerfGE 154, 152, Rn. 159.

164 BVerfGE 154, 152, Rn. 166.

165 Gärditz (Fn. 9), 829; ders. (Fn. 34), 906.

166 BT-Drs. 19/26103, S. 55.

167 Von einem „Sonderfall“ innerhalb der nachrichtendienstlichen Eingriffsermächtigungen spricht Bäcker (Fn. 65), § 28 Rn. 109; ders. (Fn. 117), S. 143 f. 


\section{Differenzierung zwischen politischer Aufklärung und sicherheitsrechtlicher Gefahrenfrüherkennung}

Wird eine nachrichtendienstliche Aufklärungsmaßnahme nicht an objektivierte Eingriffsschwellen geknüpft, sondern im Wesentlichen ausschließlich final durch den nachrichtendienstlichen Auftrag angeleitet, bedarf es weitergehender verfahrensrechtlicher Sicherungen, um die Ausrichtung auf die jeweiligen Zwecke rationalisierend zu strukturieren, kontrollierbar $\mathrm{zu}$ machen und eine entgrenzende Verselbstständigung der Befugnis zu verhindern. ${ }^{168}$ Der Mangel an objektivierten Tatbestandsvoraussetzungen wird hier ausnahmsweise nicht durch eine Qualifikation im Rechtsgüterschutz, ${ }^{169}$ sondern im Wege eines „Grundrechtsschutzes durch Verfahren“ kompensiert. Dessen Reichweite wird dabei wiederum durch den jeweiligen Zweck der Überwachungsbefugnis programmiert. So fallen die verfahrensrechtlichen Sicherungen, je nach Zwecksetzung der Aufklärungsmaßnahme - politische Information einerseits, Gefahrenfrüherkennung andererseits -, unterschiedlich aus.

\section{a) Politische Aufklärung als Grundrechtseingriff minderen Gewichts: Verzicht auf verfahrensrechtliche Sicherungen}

Der doppelfunktionale gesetzliche Auftrag der Nachrichtendienste determiniert somit die jeweils geltenden verfahrensrechtlichen Sicherungen im Rahmen der Überwachungsmaßnahmen. Danach kann etwa auf den Schutz von Vertraulichkeitsbeziehungen verzichtet werden, wenn dies erforderlich ist und die Maßnahme allein der politischen Information der Bundesregierung dient. ${ }^{170}$ Auch die einschränkenden Voraussetzungen, unter denen strategische Überwachungsmaßnahmen gezielt auf bestimmte Personen gerichtet werden dürfen, können entfallen, sofern Überwachungsmaßnahmen ausschließlich zur politischen Information der Bundesregierung bestimmt und auf diese ausgerichtet sind. ${ }^{171}$

Hinter dieser Differenzierung stehen Verhältnismäßigkeitserwägungen, im Rahmen derer die Aufklärung zur politischen Information als Grundrechtseingriff minderen Gewichts angesehen wird. ${ }^{172}$ Soweit nicht Informationen zu Personen in unmittelbar staatspolitischen Funktionen des Auslands infrage stehen, werde es im Rahmen solcher Berichte auf personenbezogene Daten oft schon nicht ankommen. Aber auch soweit es erforderlich sei, personenbezogene Informationen in die Berichte aufzunehmen, unterschieden sich solche Berichte grundlegend von der Übermittlung von Erkenntnissen über Einzelpersonen an innerstaatliche Behörden, die ihrerseits - mittelbar oder unmittelbar - mit eigenen Handlungsbefugnissen ausgestattet seien und diese unter Umständen auch gegenüber den Betroffenen einsetzen könnten. Dies gelte erst recht im Vergleich mit der Übermittlung an ausländische Stellen. „Bei der Nutzung

168 BVerfGE 154, 152, Rn. 178; Dietrich, in: Schenke/Graulich/Ruthig (Hrsg.), Sicherheitsrecht des Bundes, 2. Aufl. 2019, BNDG, § 6 Rn. 10.

$169 \mathrm{Zu}$ dieser Besonderheit im Recht der Nachrichtendienste schon oben bei Fn. 131 und 133.

170 BVerfGE 154, 152, Rn. 198.

171 BVerfGE 154, 152, Rn. 190.

172 BVerfGE 154, 152, Rn. 225. 
als Hintergrundinformation der Bundesregierung oder als Grundlage zur Vorbereitung ihrer Regierungsentscheidungen verblasst typischerweise das Interesse an den konkret betroffenen Privatpersonen, so dass die Übermittlung auch unabhängig von der Einhaltung konkreter Übermittlungsschwellen gerechtfertigt werden kann“. 173

\section{b) Gefahrenfrüherkennung als faktische Primäraufgabe: Folgewirkungen des verfassungsgerichtlichen Exklusivitätsverhältnisses}

So logisch wie naheliegend die bereichsspezifische Differenzierung in den verfahrensrechtlichen Sicherungen je nach Zwecksetzung des Aufklärungsziels - entweder politische Aufklärung oder sicherheitsrechtliche Gefahrenfrüherkennung - auf den ersten Blick erscheinen mag, so holzschnittartig ${ }^{174}$ wie praxisfremd ${ }^{175}$ erweist sich dieses Exklusivitätsverhältnis bei genauerer Betrachtung. Das verfassungsgerichtlich kreierte „Entweder-Oder“ schlägt sowohl auf den innerdeutschen als auch den internationalen Informationsaustausch durch und führt $\mathrm{zu}$ problematischen, offenkundig nicht beabsichtigten Folgewirkungen. So wird bei der politischen Information durchweg vorausgesetzt, dass eine Übermittlung der Erkenntnisse an andere Stellen prinzipiell ausgeschlossen ist. ${ }^{176}$ Eine Ausnahme hiervon kann der Gesetzgeber nur vorsehen, soweit die Daten aus sich heraus „eine unmittelbar bevorstehende Gefahr“ für Leib, Leben oder Freiheit einer Person, für lebenswichtige Güter der Allgemeinheit oder für den Bestand oder die Sicherheit des Bundes oder eines Landes erkennen lassen. ${ }^{177}$ Erlangt etwa der BND im Rahmen einer politischen Aufklärungsmaßnahme Erkenntnisse darüber, dass ein Staat den Atomwaffensperrvertrag bricht, indem er ein geheimes militärisches Atomwaffenprogramm betreibt und dafür auf verschleierten Lieferwegen technische Teile von deutschen Unternehmen bezieht, könnte er hierüber zulässigerweise zwar die Mitglieder der Bundesregierung unterrichten. Diese dürften die Informationen aber nicht an die Sicherheitsbehörden übermitteln, um eine weitere Proliferation $\mathrm{zu}$ unterbinden und strafrechtliche Ermittlungen einzuleiten, da bei einem solchen Szenario eine unmittelbar bevorstehende Gefahr für die vom Bundesverfassungsgericht bezeichneten Rechtsgüter noch nicht anzunehmen ist. ${ }^{178}$

Das Gleiche gilt im Verhältnis zu ausländischen Partnerdiensten, wirkt sich dort allerdings noch gravierender aus: Auch diesen dürften Informationen aus politischen Aufklärungsmaßnahmen niemals zur Verfügung gestellt werden, es sei denn, es liegt ausnahmsweise eine qualifizierte Gefahrenlage vor. Dies ist indessen in den seltensten Fällen vorstellbar. ${ }^{179}$ Ein Auslandsnachrichtendienst ist jedoch in besonderem Maße auf internationale Kooperation und wechselseitigen Informationsaustausch angewiesen. In der Vergangenheit haben nachweislich wiederholt Informationen ausländischer Nachrichtendienste dazu beigetragen, dass terroristische Anschlagsplanungen hierzu-

173 BVerfGE 154, 152, Rn. 225.

174 Dietrich (Fn. 12), 178.

175 Gärditz (Fn. 9), 830; Unterreitmeier (Fn. 6), 179.

176 BVerfGE 154, 152, Rn. 177.

177 BVerfGE 154, 152, Rn. 228.

178 Beispiel nach Dietrich (Fn. 12), 179.

179 Mit konkreten Anwendungsbeispielen Dietrich (Fn. 12), 180. 
lande frühzeitig aufgedeckt und Attentate von den Sicherheitsbehörden verhindert werden konnten. ${ }^{180}$ Auf die islamistische „Sauerland Gruppe“ beispielsweise wurden die Behörden im Jahr 2007 durch Hinweise der US-amerikanischen National Security Agency (NSA) aufmerksam, die abgefangene E-Mails an den BND weiterleitete. Auch der im Jahr 2018 erfolgten Festnahme des Kölner „IS“-Anhängers, der aus tausenden über das Internet bestellten Rizinus-Samen eine Bombe gebaut hat, ${ }^{181}$ waren entsprechende Hinweise eines ausländischen Geheimdienstes vorausgegangen. Diese Reziprozität, die von vitalem Sicherheitsinteresse ist, erscheint bei einer Verabsolutierung der Trennung zwischen den Aufklärungszwecken gefährdet. Das Exklusivitätsverhältnis kann in eine ,außenpolitische Sackgasse“ führen und „die Bündnisfähigkeit der Bundesrepublik beeinträchtigen“. ${ }^{182}$

Um diese „,dogmatische Anomalie“"183 zu beseitigen, hätte sich der BNDG-Reformgesetzgeber von den Vorgaben des Bundesverfassungsgerichts ein Stück weit lösen und bestimmte Fälle normieren müssen, in denen eine Weiterleitung der im Rahmen einer politischen Aufklärungsmaßnahme gewonnenen Erkenntnisse an in- und ausländische Behörden unter erleichterten Voraussetzungen zulässig ist. Eine Orientierung an den Grundsätzen der hypothetischen Datenneuerhebung, die das Bundesverfassungsgericht im BKAG-Urteil ${ }^{184}$ für die verfassungsrechtliche Zulässigkeit von zweckändernden Übermittlungen aufgestellt hat, kam dabei nicht in Betracht. ${ }^{185}$ Diese stellen darauf $a b$, ob die entsprechenden Daten nach verfassungsrechtlichen Maßstäben auch für den geänderten Zweck mit vergleichbar schwerwiegenden Mitteln neu erhoben werden dürften. Da der BND seine Daten aber nicht zu eigenen operativen Zwecken, sondern von vornherein allein mit dem Ziel der Weiterleitung erhebt, greift das Kriterium der hypothetischen Datenneuerhebung ins Leere: „Der Zweck der Datenerhebung und der Zweck der Datenübermittlung rücken insofern zusammen“. 186 Insoweit war zwar auf Ebene der Übermittlungsnormen sicherzustellen, dass die aufgrund im Wesentlichen anlassloser Befugnisse gewonnenen Erkenntnisse nur der weiteren Verarbeitung zugänglich werden, wenn eine Erhebung der Daten nach allgemeinen rechtsstaatlichen Anforderungen für die Übermittlungszwecke gerechtfertigt wäre. Im Fall der Weiterleitung von Daten aus einer allein zur politischen Information der Bundesregierung durchgeführten Aufklärungsmaßnahme lässt das Bundesverfassungsgericht jedoch die notwendige Balance zwischen rechtsstaatlicher Rigidität und sicherheitspolitischer Flexibilität vermissen und schraubt diese Anforderungen zu hoch.

Der BND-Gesetzgeber hat das verfassungsgerichtlich statuierte Exklusivitätsverhältnis gleichwohl eins-zu-eins adaptiert (vgl. §§ 29 Abs. 7, 30 Abs. 5 BNDG-neu).

180 Vgl. dazu https://netzpolitik.org/2016/bka-veroeffentlicht-liste-mit-elf-vereitelten-terrora nschlaegen/.

181 OLG Düsseldorf, BeckRS 2020, 4729, Rn. 153 ff. - Rizin-Bombenbauer.

182 Dietrich (Fn. 12), 180; zustimmend Unterreitmeier (Fn. 6), 180 f.; in der Tendenz weniger kritisch Gärditz (Fn. 9), 832; ders. (Fn. 34), 909.

183 Unterreitmeier (Fn. 6), 180.

184 BVerfGE 141, 220, Rn. $287 \mathrm{ff}$.

185 Anders Unterreitmeier (Fn. 6), 180.

186 BVerfGE 154, 152, Rn. 218; noch deutlicher Unterreitmeier (Fn. 6), 184: „sind identisch". 
Will man in der Praxis die aufgezeigten Folgewirkungen nicht sehenden Auges in Kauf nehmen, bleibt als einziger Ausweg, die Ausland-Ausland-Fernmeldeüberwachung in Zukunft nur noch - oder zumindest immer auch - zur Gefahrenfrüherkennung einzusetzen. ${ }^{187}$ Eine saubere Trennung zwischen den Funktionen der politischen Aufklärung und Sicherheitsgewährleistung erscheint ohnehin kaum möglich, da die zugrunde liegenden Szenarien regelmäßig dynamisch sind, ineinander übergehen und sich kurzfristig ändern können. So kann sich die strategische Lagebeurteilung in einem Bürgerkriegsland wie Syrien jederzeit und ohne Weiteres von der außenpolitischen Informationsfunktion zur sicherheitsrechtlichen Zielsetzung wandeln, wenn hierbei z.B. Erkenntnisse über Anschlagspläne oder die Beschaffung von Waffen und Sprengstoff in Europa bekannt werden. ${ }^{188}$ Dass sich eine sicherheitspolitische Einschätzung innerhalb kürzester Zeit grundlegend ändern und die veränderte Lage die zu ihrer Überwachung eingesetzten Behörden unvorbereitet treffen kann, wurde unlängst am Beispiel Afghanistans deutlich. ${ }^{189}$ Nur dann, wenn die Aufklärung von vornherein auch mit dem Ziel der Gefahrenfrüherkennung versehen wird, ist die Möglichkeit der Weiterleitung von Daten an inländische wie ausländische Behörden jenseits der kaum erfüllbaren Hürde der unmittelbaren Gefahr für ein hochrangiges Rechtsgut gesichert. Mit der Etablierung der sicherheitsrechtlichen Aufklärung als faktischer Primäraufgabe würde sich indes nicht nur der Charakter des BND grundlegend ändern, sondern es käme zugleich zu einer Verschiebung innerhalb der deutschen Sicherheitsarchitektur. ${ }^{190}$ Da beides vom Bundesverfassungsgericht ersichtlich nicht intendiert war, ${ }^{191}$ täte der Gesetzgeber gut daran, hier im Rahmen der ausstehenden Gesamtreform des Nachrichtendienstrechts noch einmal anzusetzen und die nötigen Weichen für eine praxisgerechte Übermittlung von Informationen zu stellen.

\section{Statuierung eines Sicherheitskooperationsrechts der Nachrichtendienste}

\section{Zwischen Rigidität und Flexibilität}

Hiermit ist insbesondere die Bedeutung eines Rechts der internationalen Nachrichtendienstkooperation in den Fokus gerückt, das in $\S \S 31-33$ BNDG-neu geregelt wird. Bei diesem handelt es sich um eine ambivalente, rechtsstaatlich heikle Materie. Denn so sehr ein Auslandsnachrichtendienst auf die Kooperation mit ausländischen Stellen angewiesen ist, so wenig kann er auf Verbleib und Nutzung der von ihm zur Verfügung gestellten Informationen Einfluss nehmen. Solange sie nicht im Inland tätig werden, sind ausländische Stellen nicht an die deutsche Rechtsordnung gebunden. Mit

187 Dietrich (Fn. 12), 180.

188 Gärditz (Fn. 9), 830.

189 In einer vertraulichen Sitzung mit Bundestagsabgeordneten sollen Vertreter des BND im Juni 2021 die Einschätzung geäußert haben, dass es nach dem Ende des NATO-Einsatzes bis zu einer Machtübernahme der radikal islamischen Taliban noch 18 bis 24 Monate dauern würde. Tatsächlich kollabierte der afghanische Staat innerhalb weniger Wochen, vgl. https://rp-online.de/politik/deutschland/afghanistan-bnd-soll-taliban-sieg-erst-fuer-2023-p rognostiziert-haben aid-62206251.

190 Dietrich (Fn. 12), $1 \overline{8} 0$.

191 Zur politischen Unterrichtung als Primärfunktion des BND vgl. oben bei Fn. 96. 
der Übermittlung in den Wirkungskreis einer anderen staatlichen und rechtlichen Ordnung gibt der Dienst die betreffenden Informationen „ohne weitere inhaltliche Kontrollmöglichkeit aus der Hand“ “. ${ }^{192}$ Dies wiederum setzt ein Mindestvertrauen in die Rechtsstaatlichkeit der Informationsverarbeitung durch ausländische Sicherheitsbehörden voraus. Ein Sicherheitskooperationsrecht der Nachrichtendienste, das darauf abzielt, die Zusammenarbeit nachrichtendienstlicher Verwaltungseinheiten über Behördengrenzen hinaus zu regulieren, ${ }^{193}$ muss danach stets einen doppelten Anspruch erfüllen: Es muss ebenso rigide wie flexibel sein, ${ }^{194}$ sowohl Ermöglichungsrecht als auch rechtsstaatliche Einhegung darstellen. ${ }^{195}$

Dieser Erkenntnis hat sich - jedenfalls im Ausgangspunkt - auch das Bundesverfassungsgericht nicht verschlossen und die besondere Bedeutung einer „möglichst effektive[n] Zusammenarbeit mit den Sicherheitsbehörden anderer Staaten" betont. ${ }^{196}$ Entsprechend sei das Grundgesetz für eine Zusammenarbeit des BND auch mit fremdstaatlichen Nachrichtendiensten offen. Zwar darf der BND danach dazu ermächtigt werden, seine Befugnisse für Erkenntnisinteressen ausländischer Dienste und Staaten zu nutzen und die gewonnenen Daten an ausländische Partnerdienste zu übermitteln. Erlaubt wird eine solche Übermittlung ins Ausland jedoch nur unter einschränkenden Voraussetzungen: Zum einen verlangt das Gericht, dass auch durch den ausländischen Umgang mit den übermittelten Daten nicht die Garantien des menschenrechtlichen Schutzes personenbezogener Daten unterlaufen werden. ${ }^{197}$ Zum anderen darf nicht zu befürchten sein, dass durch die Nutzung der Informationen elementare rechtsstaatliche Grundsätze verletzt werden. Angesichts der Spezifika nachrichtendienstlicher Aufklärungs- und Übermittlungstätigkeit, die unter Umständen auch Kontakte mit rechtsstaatlich nicht gefestigten Staaten einschließen könne, sei insbesondere sicherzustellen, dass Informationen nicht dazu genutzt werden, um bestimmte Bevölkerungsgruppen zu verfolgen, Oppositionelle zu unterdrücken, Menschen menschenrechtswidrig oder unter Verstoß gegen humanitäres Völkerrecht zu töten, zu foltern oder sie ohne rechtsstaatliche Verfahren in Haft zu nehmen. ${ }^{198}$

\section{Zwischen Vergewisserung der Rechtsstaatlichkeit und den Pfaden der Diplo- matie}

Es fragt sich, wie diese Anforderungen effektiv sichergestellt werden sollen. Zur Wahrung der von ihm aufgezeigten Schutzstandards in datenschutz- und menschen-

192 BVerfGE 154, 152, Rn. 263; vgl. auch Graulich (Fn. 12), 126.

193 Näher Gusy, Nachrichtendienste in der sicherheitsbehördlichen Kooperation, in: Dietrich/ Eiffler (Hrsg.), Handbuch des Rechts der Nachrichtendienste, 2017, Kap. IV § 2 Rn. 1 ff.; Schöndorf-Haubold, Auf dem Weg zum Sicherheitskooperationsrecht?, in: Dietrich/ Gärditz/Graulich u.a. (Hrsg.), Nachrichtendienste in vernetzter Sicherheitsarchitektur, 2020, S. 3 ff.

$194 \mathrm{Zu}$ diesem (verfassungs-) rechtlichen Zielkonflikt im Allgemeinen Schuppert, Rigidität und Flexibilität von Verfassungsrecht, AöR 120 (1995), 32 ff.

195 Gärditz (Fn. 34), 909.

196 BVerfGE 154, 152, Rn. 246.

197 BVerfGE 154, 152, Rn. 236.

198 BVerfGE 154, 152, Rn. 237. 
rechtlicher Hinsicht verlangt das Bundesverfassungsgericht normenklare gesetzliche Regelungen, die dem BND eine Vergewisserung über das Schutzniveau im Ausland aufgeben. ${ }^{199}$ Diese Rechtsstaatlichkeitsvergewisserung könne sich zunächst auf eine generalisierende tatsächliche Einschätzung der Sach- und Rechtslage in den Empfängerstaaten stützen. Die Prüfung müsse aber so gestaltet sein, dass entgegenstehende Tatsachen zur Kenntnis genommen werden und die Einschätzung erschüttert werden könne. Die rechtsstaatliche Vergewisserung hat sich letztlich ,auf gehaltvolle, realitätsbezogene und aktuelle Informationen zu stützen“. ${ }^{200}$ Das Bundesverfassungsgericht verweist in diesem Zusammenhang ausdrücklich auf die Vergewisserung über den rechtsstaatlichen Mindeststandard im Auslieferungsverfahren. ${ }^{201}$ Der Gesetzgeber ist dem verfassungsgerichtlichen Normierungsauftrag nachgekommen und hat die Anforderungen an eine entsprechende Zusicherung katalogartig in $\S 31$ Abs. 4 Satz 2 Nr. 3 BNDG-neu als Teil einer Absichtserklärung ausgeformt. ${ }^{202}$

Bei aller Sympathie für die Übertragung des Konzepts der Rechtsstaatlichkeitsvergewisserung und den hierdurch induzierten „Verfassungsverbund unter Freunden“203 erscheint doch zweifelhaft, ob sich nachrichtendienstliche Kooperation unter den weltumspannenden Bedingungen des 21. Jahrhunderts auf ein derart formalisiertes Verbund-Verwaltungshandeln zwischen demokratischen Rechts- und Verfassungsstaaten reduzieren lässt. ${ }^{204}$ Die Gefahren einer modernen globalisierten, technisierten und digitalisierten Weltrisikogesellschaft ${ }^{205}$ verlaufen $\mathrm{zu}$ unvorhersehbar, dynamisch und asymmetrisch, als dass man sich auf eine Kooperation mit „Freunden“ beschränken könnte, die grundlegende gemeinsame Werte teilen. Drohende Gefährdungen durch militärische wie nicht militärische Konfliktursachen (Terrorismus, Klimawandel, Naturkatastrophen, Hungersnöte, Pandemien, Flucht und Vertreibung) lassen sich nur durch ebenso zahlreiche wie vielfältige Erkenntnisquellen effektiv aufklären (,,allsource intelligence“). Die Rechtstaatlichkeitsvergewisserung mag im Verhältnis zu EU- und NATO-Partnern ein geeignetes (wenngleich weitgehend überflüssiges) Instrument zur Perpetuierung rechtsstaatlicher Standards bei der Verwendung der übermittelten Informationen darstellen. ${ }^{206}$ Im Übrigen folgt die Kooperation der Nachrich-

199 BVerfGE 154, 152, Rn. 238 ff.

200 BVerfGE 154, 152, Rn. 241.

201 So wird im BNDG-Urteil wiederholt Bezug genommen auf BVerfGE 140, 317, insb. Rn. 69.

202 Nach der gesetzlichen Regelung wie auch nach der Gesetzesbegründung bleibt das Verhältnis von rechtlich unverbindlicher "Absichtserklärung“ und verbindlicher „Zusicherung" allerdings diffus.

203 Vgl. Klement, Verrechtlichung der Spionage - ein „Verfassungsverbund unter Freunden“?, Vortrag v. 11.3.2021, https://elsa-mannheim.de/blog/2021/02/25/prof-dr-klement-u eber-verrechtlichung-der-spionage-ein-verfassungsverbund-unter-freunden/.

204 Gärditz (Fn. 9), 832.

205 Beck, Weltrisikogesellschaft - Auf der Suche nach der verlorenen Sicherheit, 2007.

206 Dietrich (Fn. 12), 180. Mit dem Konzept einer „Europäischen Nachrichtendienstgemeinschaft" etwa Lledo-Ferrer/Dietrich, Building a European Intelligence Community, International Journal of Intelligence and CounterIntelligence 33 (2020), $440 \mathrm{ff}$.; vgl. auch Con$\mathrm{rad}$, Europäische Nachrichtendienstkooperation, in: Dietrich/Gärditz/Graulich u.a. (Hrsg.), Reform der Nachrichtendienste zwischen Vergesetzlichung und Internationalisierung, 2019, S. 161 (165 ff.). 
tendienste eher den Pfadabhängigkeiten der Diplomatie: „Die Partner kann man sich hierbei nicht immer aussuchen“. ${ }^{207}$ Unabhängig davon bestehen die Schwierigkeiten bei der grenzüberschreitenden Kooperation der Nachrichtendienste weniger in der abstrakten Konkretisierung der rechtsstaatlichen Rahmenbedingungen als vielmehr hinsichtlich der praktischen Kontrolle und Durchsetzung ihrer Einhaltung. ${ }^{208}$ Eine Verabsolutierung des ordre public-Vorbehalts verspricht somit wenig rechtsstaatlichen Zugewinn zum Preis einer drohenden außen- und sicherheitspolitischen Autoparalyse. ${ }^{209}$

\section{Legalisierung nachrichtendienstlichen „Hackings“6}

Im Recht der Nachrichtendienste wurden zudem weitere, bisweilen als überfällig angesehene gesetzliche Grundlagen zur Infiltration informationstechnischer Systeme geschaffen. Diese verteilen sich - je nachdem, ob es um Eingriffe im Ausland oder Inland geht - auf das BNDG einerseits und das G 10 andererseits. Damit schreiben die jüngsten Reformen die überkommene Zweispurigkeit der nachrichtendienstlichen Ermächtigungsgrundlagen fort. ${ }^{210}$

\section{Cyberoperationen im Ausland}

Cyberangriffe werden mittlerweile als „das kriminelle Hauptproblem im Bereich von Internet und Digitalisierung“211 angesehen. Über die Urheberschaft derartiger Attacken aus dem digitalen Raum lässt sich oftmals nur spekulieren. Ihre Motivation kann in Cybercrime, Cyberterrorismus, Cybersabotage oder -spionage bestehen. ${ }^{212} \mathrm{Nicht}$ selten werden fremde Nachrichtendienste verdächtigt, ${ }^{213}$ sei es, dass sie selbst die entsprechenden Cyberangriffe vornehmen, sei es, dass sie sich wie der russische Militärgeheimdienst GRU privater Hackergruppen (z.B. APT28 aka. „Fancy Bear“) bedienen. Die Lahmlegung wichtiger Infrastruktureinrichtungen durch Cyberangriffe gilt dementsprechend als das größte Cyberrisiko der Gesellschaft, ${ }^{214}$ weit vor Gefahren der Überwachung der Bürger durch den deutschen Staat. ${ }^{215}$ Vor diesem Hintergrund scheint eine Steigerung der Effektivität in der nationalen Cyberabwehr rechtstatsächlich unausweichlich und - zumindest im Bereich grundrechtlicher Schutzpflichten -

207 Gärditz (Fn. 9), 832.

208 Gusy (Fn. 193), Kap. IV § 2 Rn. 89.

209 Vor einer solchen im Vorfeld der BNDG-Entscheidung warnend Gärditz (Fn. 9), 497.

$210 \mathrm{Zu}$ dieser Problematik noch VI. 3.

211 Frenz, Stärkerer staatlicher Schutz vor Cyberangriffen?, DVBl. 2019, 1021 (1021).

212 Könen, Gefahren für die innere Sicherheit aus dem Cyber-Raum, in: Sensburg (Hrsg.), Sicherheit in einer digitalen Welt, 2017, S. 45 (49 ff.).

213 Bundesamt für Verfassungsschutz, Nachrichtendienstlich gesteuerte Cyberangriffe, 2018, S. $6 \mathrm{ff}$.

214 Zur Vulnerabilität der Gesellschaft aufgrund von Cyberangriffen exemplarisch Guckelberger, Energie als kritische Infrastruktur, DVBl. 2015, $1213 \mathrm{ff}$.

215 Vgl. Deloitte, Cyber Security Report 2017 - Teil 1, S. 9. 
verfassungsrechtlich geboten. ${ }^{216}$ Eine „Lizenz zum Hacken“ kann den Nachrichtendiensten - wie auch immer diese im Einzelnen ausgestaltet sein soll - jedoch nur auf gesetzlicher Grundlage (Art. 20 Abs. 3 GG) erteilt werden. ${ }^{217}$

Komplementär zu § 19 Abs. 6 BNDG-neu (zur Durchführung strategischer Aufklärungsmaßnahmen) hat der Gesetzgeber mit $\S \S 34 \mathrm{ff}$. BNDG-neu nun erstmals Befugnisregelungen für individualbezogene Eingriffe in das aus Art. 2 Abs. 1 i.V.m. Art. 1 Abs. 1 GG $^{218}$ folgende Grundrecht auf Vertraulichkeit und Integrität informationstechnischer Systeme im Ausland geschaffen. Diese sind überaus umstritten: Teilweise werden sie mit Blick auf die Aufgabenerfüllung des BND für „unverzichtbar“ gehalten, ${ }^{219}$ teilweise sieht man in ihnen bedenkliche, weil die IT-Sicherheit gefährdende Formen staatlichen „Hackings““. ${ }^{220}$ Mit $§ 34$ Abs. 1 Satz 1 BNDG-neu ist die Infiltration eines informationstechnischen Systems im Wege einer Computer Network Exploitation (CNE) eröffnet, um entweder eine Online-Durchsuchung oder eine Quellen-Telekommunikationsüberwachung zu ermöglichen. Das erscheint insoweit konsequent, als das Bundesverfassungsgericht im BNDG-Urteil ${ }^{221}$ obiter dictum erklärt hat, dass es auch belastbarer (gesetzlicher) Eingriffsschwellen bedürfe, wenn im Wege der Einzelanordnung Überwachungsmaßnahmen im Ausland in Form einer Online-Durchsuchung angeordnet würden. ${ }^{222}$

\section{Staatstrojaner im Inland}

Darüber hinaus hat der Gesetzgeber mit dem Gesetz zur Anpassung des Verfassungsschutzrechts vom 5. Juli $2021^{223}$ eine gesetzliche Ermächtigungsgrundlage für entsprechende Inlandseingriffe geschaffen und diese auf sämtliche Nachrichtendienste erstreckt. Mit den Anpassungen reagiert der Normgeber zum einen auf aktuelle Gefährdungen im Bereich des Rechtsterrorismus, zum anderen auf die ,gewandelten Kommunikationsgewohnheiten unter Nutzung moderner Technik". ${ }^{224}$ Letzteres richtet sich primär gegen die Ende-Zu-Ende-Verschlüsselung (E2E) bei Messenger-Diensten wie WhatsApp, Wire oder Signal. Bei diesen klafft aus der Perspektive der Sicherheits- und Strafverfolgungsbehörden seit dem Jahr 2016 eine Aufklärungslücke, die mit der Neuregelung geschlossen werden soll. ${ }^{225}$

216 Eingehend dazu Brunst, Cyberabwehr, in: Dietrich/Eiffler (Hrsg.), Handbuch des Rechts der Nachrichtendienste, 2017, Kap. V § 7 Rn. 44 ff.; vgl. auch Frenz (Fn. 211), 1022 ff.; Klatt, Cyber-Security als Rechtsstaatspflicht, JuWissBlog 101/2019, https://www.juwiss.d e/101-2019/.

217 Im Einzelnen Barczak, Lizenz zum Hacken?, NJW 2020, 595 ff.; vgl. auch Amthor, Aktive sicherheitsbehördliche Cyberabwehr, GSZ 2020, $251 \mathrm{ff}$.

218 Grundlegend BVerfGE 120, 274 (303 ff.) - Online-Durchsuchungen.

219 Graulich (Fn. 12), 127.

220 Landefeld, Schriftliche Stellungnahme an den Innenausschuss v. 18.2.2021, AusschussDrs. 19(4)731 E, S. 2, 5.

221 BVerfGE 154, 152, Rn. 156.

222 Dietrich (Fn. 35), Ausschuss-Drs. 19(4)731 G, S. 12.

223 BGBl. I S. 2274.

224 BT-Drs. 19/24785, S. 14

225 BT-Drs. 19/24785, S. 22. 


\section{a) Verschwimmende Grenzen}

Der entsprechende „Staatstrojaner für Nachrichtendienste“226 wird in $\S 11$ Abs. 1 a G 10 geregelt. Die Regelung orientiert sich am Modell der Strafprozessordnung (vgl. $\S 100$ a Abs. 1 Satz 2 und 3 sowie Abs. 5 und 6 StPO) ${ }^{227}$ und differenziert wie diese zwischen der „normalen“ Quellen-TKÜ (Satz 1) einerseits und der „erweiterten“ Quellen-TKÜ (Satz 2) andererseits. Die in $\S 100$ b StPO eigens geregelte OnlineDurchsuchung wird von $\S 11$ Abs. 1 a G 10 demgegenüber nicht übernommen. Im Unterschied zur Online-Durchsuchung ist die Quellen-TKÜ grundsätzlich auf die während der laufenden Kommunikation in einem bestimmten Zeitraum anfallenden (,fließenden") Kommunikationsinhalte zu beschränken. Darüber hinaus dürfen nur solche Inhalte und Umstände der Kommunikation überwacht und aufgezeichnet werden, bei denen der Übertragungsvorgang bereits abgeschlossen ist und die auf dem informationstechnischen System des Betroffenen in einer Anwendung gespeichert sind. ${ }^{228}$ Die Quellen-TKÜ steht in funktionaler Äquivalenz zur Überwachung und Ausleitung der Nachrichten aus dem Telekommunikationsnetz im Rahmen der herkömmlichen Telekommunikationsüberwachung. ${ }^{229}$ Um dies auch in zeitlicher Hinsicht zu gewährleisten, ist technisch sicherzustellen, dass insbesondere über Messenger-Dienste versandte Nachrichten erst ab dem Zeitpunkt der Anordnung durch die zuständige oberste Landesbehörde bzw. das Bundesinnenministerium (vgl. § 10 Abs. 1 G 10) ausgeleitet werden dürfen.

Soweit bei der „erweiterten“ Quellen-TKÜ eine Überwachung und Aufzeichnung der auf dem informationstechnischen System des Betroffenen gespeicherten Inhalte und Umstände der Kommunikation ermöglicht wird (vgl. § 11 Abs. 1 a Satz 2 G 10, $\S 100$ a Abs. 1 Satz 3 StPO), verschwimmen allerdings die Grenzen zwischen Quellen-TKÜ und Online-Durchsuchung. Dem versucht der Gesetzgeber zwar dadurch zu begegnen, dass gespeicherte Nachrichten nicht erhoben werden dürfen, wenn sie nicht mehr als aktuelle Kommunikation im Zeitraum nach Ergehen der Anordnung gelten können. Ebenso wie bei der Sprach- und Videotelefonie darf das Ausleiten von Messenger-Nachrichten am Endgerät danach nur dann erfolgen, wenn dies ein funktionales Äquivalent zur Überwachung und Ausleitung der Nachrichten aus dem Telekommunikationsnetz darstellt. Eine wirksame Abgrenzung zwischen Quellen-TKÜ und Online-Durchsuchung ist damit jedoch nicht gewährleistet. ${ }^{230}$ So bleibt ungeklärt, ob über die erweiterte Quellen-TKÜ nur auf Daten zugegriffen werden darf, die ab dem

226 Poscher/Kappler, Staatstrojaner für Nachrichtendienste: Zur Einführung der Quellen-Telekommunikationsüberwachung im Artikel 10-Gesetz, VerfBlog, 2021/7/06, https://verfas sungsblog.de/staatstrojaner-nachrichtendienste/.

227 Eingefügt durch Gesetz zur effektiveren und praxistauglicheren Ausgestaltung des Strafverfahrens v. 17.8.2017, BGBl. I S. 3202.

$228 \mathrm{Zu} \S 100$ a Abs. 1 Satz 3 StPO Bruns, in: KK-StPO, 8. Aufl. 2019, § 100 a Rn. 44.

229 So die Begründung des Rechtsausschusses zur StPO-Reform, die sich auf die Regelung im G 10 übertragen lässt, vgl. BT-Drs. 18/12785, S. 50.

230 Poscher/Kappler (Fn. 226); dies., Schriftliche Stellungnahme an den Innenausschuss v. 17.5.2021, Ausschuss-Drs. 19(4)844 E, S. 5; vgl. auch BGH, NJW 2021, 1252, Rn. 24 Zugriff auf „ruhende“ E-Mails, der die „Nähe“ der erweiterten Quellen-TKÜ zur OnlineDurchsuchung ebenfalls betont, aber eine effektive Abgrenzung über § 100 a Abs. 5 StPO bei der Durchführung im Einzelfall gewährleistet sieht. 
Zeitpunkt der Anordnung kommuniziert wurden, oder ob die Regelung auch gespeicherte Kommunikationsverläufe erfassen soll, die möglicherweise Jahre zurückreichen, aber nach dem Anordnungszeitpunkt über einen Dienst noch mit der aktuellen Kommunikation „mitkommuniziert“ werden. WhatsApp-Backups können etwa große Mengen an monate- oder jahrelanger Kommunikation enthalten, die vor der behördlichen Anordnung erfolgt ist, aber von der aktuellen Telekommunikation mitumfasst werden kann. ${ }^{231}$

Darüber hinaus leitet sich der Begriff der Quellen-TKÜ davon ab, dass sie für das Auslesen an der „Quelle“ selbst ansetzt; hierzu ist allerdings schon technisch eine Infiltration des Systems erforderlich, sei es durch eine unmittelbar physische Einwirkung auf das Gerät, sei es durch das Ausnutzen bestehender Software-Schwachstellen. ${ }^{232}$ Im Ergebnis handelt es sich bei $\S 11$ Abs. 1 a Satz 2 G 10 um eine ,kleine Online-Durchsuchung“233 bzw. eine „Mischform“234 zwischen Quellen-TKÜ und Online-Durchsuchung. Dies wirkt sich in der verfassungsrechtlichen Bewertung aus. ${ }^{235}$

\section{b) Verfassungsrechtliche Bedenken}

Abgesehen davon, dass der praktische Mehrwert des Aufbrechens der E2E-Verschlüsselung überschaubar bleiben dürfte, weil Kriminelle und Terroristen ohne großen Aufwand auf andere Kommunikationskanäle ausweichen können, begegnet die Regelung im G 10 gesetzessystematischen wie verfassungsrechtlichen Bedenken. Schon der systematische Standort der neuen Befugnisnorm in $\S 11$ Abs. 1 a G 10 irritiert: Die maßgebliche Ermächtigungsgrundlage für Beschränkungen in Einzelfällen findet sich in $\S 3$ G 10. Demgegenüber wird die Neuregelung inmitten des 4. Abschnitts über das „Verfahren“ verankert. Die Platzierung der Befugnisnorm zwischen Verfahrenserfor-

231 Vgl. die Begründung einer Verfassungsbeschwerde von 64 FDP-Abgeordneten gegen das Gesetz zur Anpassung des Verfassungsschutzrechts, Juli 2021, S. 77, abrufbar unter https: //www.fdpbt.de/sites/default/files/2021-07/20210714_VfB_Pressefassung.pdf.

232 Im Einzelnen Blechschmitt, Zur Einführung von Quellen-TKÜ und Online-Durchsuchung, StraFo 2017, 361 ff.; Derin/Golla, Der Staat als Manipulant und Saboteur der ITSicherheit?, NJW 2019, $1111 \mathrm{ff}$.

233 Wie hier Freiling/Safferling/Rückert, Quellen-TKÜ und Online-Durchsuchung als neue Maßnahmen für die Strafverfolgung, JR 2018, 9 (11): „eine zeitlich und inhaltlich beschränkte Form der Online-Durchsuchung und nicht [...] eine Form der Telekommunikationsüberwachung“; Martini/Fröhlingsdorf, Catch me if you can: Quellen-Telekommunikationsüberwachung zwischen Recht und Technik, NVwZ 2020, 1803 (1803): „,kleine Schwester" der Online-Durchsuchung“; a.A. Graf, in: BeckOK-StPO, Stand: 1.1.2021, $\S 100$ a Rn. 123: keine „kleine Online-Durchsuchung“.

234 Poscher/Kappler (Fn. 226); dies. (Fn. 230), Ausschuss-Drs. 19(4)844 E, S. 5; Blechschmitt, Strafverfolgung im digitalen Zeitalter, MMR 2018, 361 (365): „,̈̈berlappen offenkundig“.

235 Für die erweiterte Quellen-TKÜ nach $\S 100$ a Abs. 1 Satz 3 StPO entsprechend Singelnstein/Derin, Das Gesetz zur effektiveren und praxistauglicheren Ausgestaltung des Strafverfahrens, NJW 2017, 2646 (2647f.): „Technisch besehen ist auch die Quellen-TKÜ eine Online-Durchsuchung [...]. Die Vorschrift ist daher nicht mehr nur am Fernmeldegeheimnis, sondern am deutlich strengeren Computer-Grundrecht zu messen, dessen Anforderungen die Voraussetzungen des $\S 100$ a StPO nicht genügen“. 
dernissen wie Antrag, Anordnung und Mitteilung an Betroffene verschleiert den eingriffsintensiven Charakter dieser Neuregelung.

Verfassungsrechtlich deutlich problematischer als der Standort innerhalb des G 10, ist die Verankerung im G 10. Das „Artikel 10-Gesetz - G 10“ dient schon seinem Namen nach exklusiv „,zur Beschränkung des Brief-, Post- und Fernmeldegeheimnisses“, mithin zur Ausfüllung des in Art. 10 Abs. 2 Satz 1 GG normierten Gesetzesvorbehalts. Damit korrespondieren die Konkretisierung des Gesetzesgegenstands in $\S 1$ Abs. 1 G 10 sowie das als eingeschränkt zitierte Grundrecht in $\S 21 \mathrm{G} 10$. Unabhängig davon, ob das Recht auf Vertraulichkeit und Integrität informationstechnischer Systeme aus Art. 2 Abs. 1 i.V.m. Art. 1 Abs. 1 GG dem Zitiergebot nach Art. 19 Abs. 1 Satz 2 GG unterfällt - wofür im Ergebnis gute Gründe sprechen ${ }^{236}$-, zeigt der Gesetzgeber mit der Normierung in $\S 11$ Abs. 1 a G 10, dass er von einem exklusiven Eingriff in das Telekommunikationsgeheimnis ausgeht. Art. 10 Abs. 1 GG schützt jedoch gerade nicht davor, dass staatliche Stellen die Nutzung eines informationstechnischen Systems als solches überwachen oder auf die Speichermedien des Systems zugreifen. Eine solche Maßnahme ist vielmehr - darin liegt gerade seine Existenzberechtigung - am IT- bzw. Computer-Grundrecht aus Art. 2 Abs. 1 i.V.m. Art. 1 Abs. 1 GG zu messen. ${ }^{237}$ Art. 10 Abs. 1 GG ist hingegen nur dann der alleinige grundrechtliche Maßstab für die Beurteilung einer Ermächtigung zu einer Quellen-TKÜ, wenn sich die Überwachung ausschließlich auf Daten aus einem laufenden Telekommunikationsvorgang beschränkt. ${ }^{238}$ Dies ist, wie oben dargelegt, bei der „erweiterten“" Quellen-TKÜ nach $\S 11$ Abs. 1 a Satz 2 G 10 indes weder der Fall noch entspricht es der Intention des Gesetzgebers. Diese „Selbsttäuschung“ zeigt deutlich, dass sich der Gesetzgeber keine ausreichenden Gedanken darüber gemacht hat, wie ein solch intensiver und neuartiger Grundrechtseingriff den verfassungsrechtlichen Vorgaben entsprechend geregelt und seiner neuartigen Eingriffsqualität Rechnung getragen werden kann. ${ }^{239}$

Dass die Ermächtigung zu Eingriffen in das Recht auf Vertraulichkeit und Integrität informationstechnischer Systeme im Artikel 10-Gesetz deplatziert ist und verfassungsrechtlich nicht trägt, zeigt sich schließlich an $\S 13$ G 10: Der Rechtsschutz gegen Beschränkungsmaßnahmen nach $\S 3$ G 10 wird hier pauschal ausgeschlossen. Hätte der Gesetzgeber, was systematisch geboten gewesen wäre, die Vorschrift des $\S 3$ G 10 um eine eigenständige Befugnis für die Quellen-TKÜ ergänzt, würde sich der Rechtsschutzausschluss auch auf diese erstrecken. Diese Ausnahme von der Garantie effektiven Rechtsschutzes nach Art. 19 Abs. 4 GG findet ihre verfassungsunmittelbare Rechtfertigung indes wiederum exklusiv in Art. 10 Abs. 2 Satz 2 GG. Mit Blick auf Art. 2 Abs. 1 i.V.m. Art. 1 GG enthält das Grundgesetz keine entsprechende Regelung.

236 Vgl. nur Sachs, in: ders. (Hrsg.), GG, 9. Aufl. 2021, Art. 19 Rn. 29. Offen gelassen in BVerfGE 120, 274 (340).

237 BVerfGE 120, 274 (307 f.).

238 BVerfGE 120, 274 (309); bestätigt in BVerfGE 141, 220, Rn. 234; BVerfG, NJW 2016, 3508, Rn. 41.

239 Poscher/Kappler (Fn. 226); dies. (Fn. 230), Ausschuss-Drs. 19(4)844 E, S. 4 f. 


\section{Etablierung neuer Kontrollstrukturen}

\section{Notwendigkeit einer zweigleisigen Kontrolle}

Die wohl anspruchsvollste Aufgabe, ${ }^{240}$ die das Bundesverfassungsgericht dem Gesetzgeber im BNDG-Urteil aufgegeben hat, bestand in der Ausgestaltung einer unabhängigen objektivrechtlichen Kontrolle der technischen Aufklärung - einschließlich des Eingriffs in informationstechnische Systeme von Ausländern im Ausland ${ }^{241}$ - und damit einhergehender Übermittlungen und Kooperationen der Nachrichtendienste. Die Regelungen in den $\S \S 40-58$ BNDG-neu können insofern durchaus als das „Herzstück der verfahrensrechtlichen Sicherungen“242 im Kontext der BNDG-Novelle betrachtet werden. Die ebenso differenzierten wie bemerkenswert detaillierten ${ }^{243}$ Kontrollvorgaben knüpfte das Gericht nicht an die in Art. 10 Abs. 2 Satz 2 und Art. 45 d GG verankerten verfassungsrechtlichen Grundentscheidungen zum Recht der Nachrichtendienste an, ${ }^{244}$ sondern schöpfte sie - ebenso freihändig wie freischwebend ${ }^{245}$ aus dem Verhältnismäßigkeitsgrundsatz. ${ }^{246} \mathrm{Um}$ den im Bereich der strategischen Telekommunikationsüberwachung strukturell bestehenden Defiziten hinsichtlich Transparenz und individuellen Rechtsschutzes zu begegnen, verlangt das Bundesverfassungsgericht zwei verschiedene Arten von Kontrolle, die sich auch organisationsrechtlich abbilden müssen. ${ }^{247}$ Die Kontrollinstitute bilden das maßgebliche Instrumentarium zur Garantie einer „Transparenz der Intransparenz“. ${ }^{248}$ Darüber hinaus schafft die Kontrolle einen Ausgleich für die im Wesentlichen nur finale Anleitung der strategischen Fernmeldeaufklärung und dient dazu, eine verfahrensmäßige Strukturierung der Handhabung dieser Befugnisse abzusichern. ${ }^{249}$

\section{a) Gerichtsähnliche und administrative Rechtskontrolle}

Die hiernach geforderte zweigleisige Kontrolle umfasst zunächst eine mit abschließenden Entscheidungsbefugnissen ausgestattete und gerichtsähnlich ausgestaltete Stelle. Ihr Kontrollzugriff, dem die wesentlichen verfahrensrechtlichen Schritte der technischen Aufklärung unterliegen, habe die Schutzaufgabe zu erfüllen, die sonst dem Richtervorbehalt und nachträglichen Rechtsschutzmöglichkeiten, insbesondere Feststellungsklagen, zukomme. ${ }^{250}$ Während der Richtervorbehalt bei verdeckten nachrichtendienstlichen Überwachungsmaßnahmen schnell an seine Funktions- und

240 Aust (Fn. 12), 723; ähnlich Durner (Fn. 12), 954.

241 Siehe oben IV. 1.

242 Graulich (Fn. 12), 127.

243 Durner (Fn. 12), 953; Gärditz (Fn. 34), 912.

244 Dafür noch Lindner/Unterreitmeier (Fn. 30), 174.

245 Dies ebenfalls monierend Gärditz (Fn. 34), 910, 912.

246 BVerfGE 154, 152, Rn. 265.

247 BVerfGE 154, 152, Rn. $274 \mathrm{ff}$.

248 Masing, in: Dietrich/Gärditz/Graulich u.a. (Fn. 18), S. 13. Zustimmend Bantlin, Die G 10Kommission - Zur Kontrolle der Nachrichtendienste, 2021, S. 19 f.

249 BT-Drs. 19/26103, S. 101.

250 BVerfGE 154, 152, Rn. 275. 
Leistungsgrenzen stößt, ${ }^{251}$ scheiterten nachträgliche Feststellungsklagen gegen die strategische Telekommunikationsüberwachung in der Vergangenheit regelmäßig daran, dass die Kläger nicht mit hinreichender Gewissheit darzulegen vermochten, dass ihr Telekommunikationsverkehr im Zuge der strategischen Beschränkung tatsächlich erfasst wurde. ${ }^{252}$ Bei seiner Konzeption einer unabhängigen gerichtsähnlichen Kontrolle hat sich das Bundesverfassungsgericht am Modell Großbritanniens orientiert, ${ }^{253}$ das seine Geheimdienste MI6 und GCHQ vor Kurzem unter strenge richterliche Aufsicht gestellt hat. ${ }^{254}$

Auf dem zweiten Gleis des Kontrollregimes rangiert eine unabhängige Rechtskontrolle administrativen Charakters. Dieser verwaltungsinternen Kontrollinstanz müsse es möglich sein, eigeninitiativ stichprobenmäßig den gesamten Prozess der technischen Überwachung auf seine Rechtmäßigkeit zu prüfen. Dies betrifft sowohl Einzelentscheidungen und Verfahrensabläufe als auch die Gestaltung der Datenverarbeitung und der Filterprozesse sowie der hierfür verwendeten technischen Hilfsmittel. Anders als der gerichtsähnlich auszugestaltenden Stelle müsse der Administrativkontrolle keine abschließende Entscheidungsbefugnis zukommen; vielmehr reichten insoweit ein Beanstandungsrecht und die Möglichkeit, zur Klärung grundlegender Rechtsfragen das gerichtsähnliche Entscheidungsgremium anzurufen. ${ }^{255}$

\section{b) Kontrolle ohne Behinderung durch die „Third Party Rule“}

Die Effektivität der Kontrolle darf schließlich nicht unter Berufung auf die „Third Party Rule" behindert werden. ${ }^{256}$ Diese besagt im Wesentlichen, dass übermittelte Informationen nicht ohne Zustimmung des Informationsgebers an Dritte weitergegeben oder für andere Zwecke verwendet werden dürfen. Ihr wird als Auskunftsverweigerungsgrund gegenüber Strafverfolgungsbehörden und Gerichten Bedeutung beigemessen. Ob dieser rechtlich nicht verbindliche, aber auf Vereinbarung mit anderen Diens-

251 Im Einzelnen Weisser, Der Richtervorbehalt im Nachrichtendienstrecht, DÖV 2014, 831 (833 ff.).

252 Vgl. BVerwGE 149, 359, Rn. 20 ff.; 157, 8, Rn. 14 ff.; kritisch hierzu Schantz, Rechtsschutz gegen die strategische Fernmeldeüberwachung: Ein „blinder Fleck“ im Rechtsstaat?, NVwZ 2015, $873 \mathrm{ff}$.

253 Überblicksweise McKay/Walker, Intelligence law in the United Kingdom, in: Dietrich/ Gärditz/Graulich u.a. (Hrsg.), Reform der Nachrichtendienste zwischen Vergesetzlichung und Internationalisierung, 2019, S. $119 \mathrm{ff}$.

254 Mit dem Investigatory Powers Act 2016 v. 29.11.2016 hat Großbritannien das System einer „Doppelten Absicherung“ (,double lock“) im Verfahren der Anordnung geheimdienstlicher Maßnahmen eingeführt. Danach muss nach der Autorisierung durch ein Mitglied der britischen Regierung zusätzlich die Genehmigung eines Richters (sog. Investigatory Powers Commissioner's Office, IPCO) eingeholt werden. Dieses Gesetz wird allgemein als Reaktion auf die öffentliche Kontroverse und die gerichtlichen Auseinandersetzungen interpretiert, die sich aus den Snowden-Enthüllungen über Massenüberwachung durch das GCHQ und die Five Eyes ergeben haben, vgl. statt vieler die Sachverständige Silkie Carlo im NSA-Untersuchungsausschuss, Deutscher Bundestag - Stenografisches Protokoll 120 I, S. 16.

255 BVerfGE 154, 152, Rn. 276.

256 BVerfGE 154, 152, Rn. 292 ff. 
ten beruhende, verwaltungspraktische Grundsatz nachrichtendienstlicher Zusammenarbeit auch gegenüber Kontrollorganen des Parlaments und selbst gegenüber Aufsichtsbehörden gilt, hat das Bundesverfassungsgericht zwar offengelassen. ${ }^{257}$ Für die Ausgestaltung der Rechtskontrolle maßgeblich ist jedoch, dass der Begriff des „Dritten“ im Sinne der „Third Party Rule“ nicht allgemein definiert ist, sondern sich nach der organisatorischen Ausgestaltung und entsprechenden Vereinbarungen richtet. ${ }^{258}$ Durch die Art der Ausgestaltung der Kontrollinstanzen sowie durch veränderte Absprachen mit den ausländischen Diensten können insofern die Bedingungen dafür geschaffen werden, dass die mit der Rechtskontrolle betrauten Instanzen nicht (mehr) als „Dritte“ angesehen werden. Auf diese Weise lasse sich gewährleisten, dass sich sowohl die verfassungsrechtlich gebotene Kontrolltätigkeit ungehindert von der „Third Party Rule“ auch auf den Umgang des BND mit von ausländischen Diensten stammenden Informationen erstreckt, als auch die für die Wahrung der außen- und sicherheitspolitischen Interessen der Bundesrepublik besonders bedeutsame Zusammenarbeit des BND mit anderen Nachrichtendiensten weitergeführt werden kann. ${ }^{259}$

\section{Unabhängiger Kontrollrat (UKR)}

Was sich in der Entscheidung des Bundesverfassungsgerichts noch so liest, als handelte es sich bei der gerichtsähnlichen und der administrativen Kontrolle um zwei auch organisatorisch - zu trennende Facetten, hat der Gesetzgeber - im Rahmen des ihm zustehenden Spielraums ${ }^{260}$ - zu zwei schlichten Kontrollfunktionen ausgeformt und diese unter dem einheitlichen institutionellen Dach eines Unabhängigen Kontrollrats (UKR) zusammengeführt (vgl. § 40 BNDG-neu). Diese Verklammerung erscheint angesichts der ohnehin bestehenden Zersplitterung ${ }^{261}$ der Kontrollinstanzen sinnvoll. Im Bereich der Nachrichtendienste des Bundes verteilen sich diese auf das Parlamentarische Kontrollgremium (PKGr, vgl. Art. 45 d GG), die G 10-Kommission ( $\$ 15$ G 10), das Vertrauensgremium ( $\$ 10$ a Abs. 2 BHO), das Gremium nach Art. 13 Abs. 6 Satz 2 GG, den Bundesbeauftragten für den Datenschutz und die Informationsfreiheit (BfDI) sowie den Bundesrechnungshof. ${ }^{262}$ Als nicht ständige, aber im Recht der Nachrichtendienste verbreitete Kontrollinstanz ließe sich noch der Untersu-

257 BVerfGE 143, 101, Rn. 163 - NSA-Selektorenlisten; hierzu Schöndorf-Haubold (Fn. 193), S. 25; Chr. Möllers, Von der Kernbereichsgarantie zur exekutiven Notstandsprärogative: zum BND-Selektoren-Beschluss des BVerfG, JZ 2017, 271 (276); verneinend etwa Gärditz, „Third Party Rule“, DVBl. 2015, 903 (907).

258 BVerfGE 154, 152, Rn. 294.

259 BVerfGE 154, 152, Rn. 295.

260 Den erheblichen gesetzgeberischen Spielraum betonend BVerfGE 154, 152, Rn. 277.

261 Ähnlich Gusy, Grundrechte und Verfassungsschutz, 2011, S. 133: „Gestrüpp von Gremien, Ausschüssen und Kommissionen“; Gärditz (Fn. 41), 532: „wirkungsarmer KontrollOverkill“.

262 Vgl. Hirsch, Die Kontrolle der Nachrichtendienste, 1996, S. 101 ff.; Kornblum (Fn. 3), S. $79 \mathrm{ff}$. 
chungsausschuss (Art. 44 GG) ergänzen. ${ }^{263}$ In dieses Kontrollgeflecht muss sich der UKR mit seinen beiden Kontrollfunktionen einfügen.

\section{a) Weisungsfreies und unabhängiges Kontrollorgan eigener Art}

Bei dem bikameralen Kontrollgremium handelt es sich um eine Ergänzung und Fortentwicklung des erst im Jahr 2016 ins Leben gerufenen, in seiner rechtlichen Struktur allerdings diffus gebliebenen Unabhängigen Gremiums (UGr, vgl. § 16 BNDG). ${ }^{264}$ Der UKR bildet eine unabhängige und weisungsfreie oberste Bundesbehörde ( $\$ 41$ Abs. 1, 3 BNDG-neu). Während ,unabhängig“" nach der Gesetzesbegründung bedeutet, dass es weder eine rechtliche Abhängigkeit geben darf noch, dass wirtschaftlicher, politischer oder sonstiger Druck auf das Gremium ausgeübt wird, soll mit „weisungsfrei“" gemeint sein, dass das Gremium bei der Ausübung der ihm gesetzlich zugewiesenen Tätigkeit faktisch keinen Beschränkungen und Einflussnahmen von dritter Seite unterworfen ist. ${ }^{265}$ Damit wird zum einen der verfassungsgerichtlichen Forderung nach richterlicher Unabhängigkeit (vgl. Art. 97 Abs. 1 GG, §26 DRiG) bei der gerichtsähnlichen Rechtskontrolle Rechnung getragen und sichergestellt, dass sich die verfassungsrechtlich gebotene Kontrolltätigkeit ungehindert von der „Third Party Rule" auch auf den Umgang des BND mit von ausländischen Diensten stammenden Informationen erstreckt.

Zum anderen ist mit Blick auf die gerichtsanaloge Ausgestaltung gewährleistet, dass durch den UKR kein ministerialfreier Raum geöffnet wird, der nach dem Demokratieprinzip (Art. 20 Abs. 2 Satz 1 GG) geschlossen bleiben müsste. Mit der Ausgestaltung des UKR als oberste Bundesbehörde wird die Rechtskontrolle des BND in Bezug auf die technische Aufklärung zwar organisatorisch an die Exekutive angebunden, ohne in Verwaltungsorganisation und -hierarchie eingebunden zu sein. ${ }^{266}$ Denn funktional ist der UKR der Judikative zuzuordnen. ${ }^{267}$ Die Frage nach einer zulässigen Ausnahme vom Regelmodell ununterbrochener Legitimation stellt sich somit nicht. ${ }^{268}$ Wenngleich mit dieser Qualifizierung verfassungsdogmatisch wenig gewonnen ist, kann man den UKR im Ergebnis als Kontrollorgan sui generis ansehen. ${ }^{269}$

263 Arndt, Parlamentarische Kontrolle der Nachrichtendienste, in: Schneider/Zeh (Hrsg.), Parlamentsrecht und Parlamentspraxis in der Bundesrepublik Deutschland, 1989, §50 Rn. 5. Zum Verhältnis zwischen PKGr und Untersuchungsausschuss Grzeszick, Grenzen des parlamentarischen Untersuchungsrechts und Kompetenzen des Parlamentarischen Kontrollgremiums, DÖV 2018, 209 (215).

264 Zu letzterem Dietrich (Fn. 168), BNDG, § 16 Rn. 1 ff.; Waldhoff, Die reformierte Kontrolle der Nachrichtendienste durch das Parlamentarische Kontrollgremium und das Unabhängige Gremium, in: Dietrich/Gärditz/Graulich u.a. (Hrsg.), Reform der Nachrichtendienste zwischen Vergesetzlichung und Internationalisierung, 2019, S. 73 (87f.).

265 BT-Drs. 19/26103, S. 102.

266 BT-Drs. 19/26103, S. 102.

267 Wie hier Gärditz (Fn. 34), 911. So schon zum UGr Dietrich (Fn. 168), BNDG, § 16 Rn. 3; a.A. Graulich (Fn. 41), 50; Marxsen (Fn. 41), 225: Verwaltungsorgan.

268 Insoweit grundlegend BVerfGE 107, 59 (87 ff.) - Lippeverband.

269 So für das UGr Dietrich (Fn. 168), BNDG, § 16 Rn. 3; Brissa, Aktuelle Entwicklungen der parlamentarischen Kontrolle nachrichtendienstlicher Tätigkeit des Bundes, DÖV 2017, 765 (773). 


\section{b) Offene Fragen}

So sehr der Gesetzgeber bei der Regelung des UKR auch bemüht war, den verfassungsgerichtlichen Vorgaben Rechnung zu tragen, so wenig geklärt sind dennoch zentrale Fragen seiner Ausgestaltung. So werden nicht nur die Besetzungsregelung ( $\$ 43$ BNDG-neu) und das Personalmanagement des UKR kritisiert. ${ }^{270}$ Vielmehr stehen dem UKR weder wirksame Instrumente zur Verfügung, um der gebotenen unabhängigen Rechtskontrolle effektiv zur Durchsetzung zu verhelfen, noch wird sein Verhältnis zum PKGr als dem verfassungsunmittelbar verankerten (Art. $45 \mathrm{~d}$ GG) und im Rahmen der letzten BNDG-Reform ${ }^{271}$ substantiell aufgewerteten Hilfsorgan des Bundestages abschließend deutlich. ${ }^{272}$ Ausdrücklich normiert werden lediglich eine halbjährliche Berichtspflicht des UKR gegenüber dem PKGr (§55 BNDG-neu) sowie der regelmäßige Austausch zwischen beiden Organen ( 58 BNDG-neu). Dabei wird ausdrücklich betont, dass die Rechte des PKGr zur Kontrolle der Bundesregierung im Hinblick auf die Tätigkeit des BND durch die Tätigkeit des UKR unberührt bleiben (§ 58 Abs. 2 BNDG-neu).

Wie dies zu lesen ist, wird von der Gesetzesbegründung nicht geklärt. ${ }^{273}$ Nicht abwegig erschiene es, wenn der UKR als organisationsrechtlich der Exekutive zuzuordnendes Gremium, das - soweit es in die präventive Kontrolle von Anordnungen ${ }^{274}$ oder die vorherige Prüfung von Übermittlungen ${ }^{275}$ eingebunden ist - als eine Art BND-interne Genehmigungsbehörde fungiert, der Kontrolle des PKGr unterfiele. ${ }^{276}$ Dies kann aus Sicht des Bundesverfassungsgerichts freilich kaum gewollt sein: Andernfalls fiele das aufwändig ausgeklügelte Modell der strikten Trennung von parlamentarisch-politischer und rechtlicher Kontrolle vollständig in sich zusammen. ${ }^{277}$ Dies hätte zudem für die „Third Party Rule“ Konsequenzen: Übte das PKGr die Kontrolle über den UKR aus, wäre die gebotene strikte Geheimhaltung operativer Informationen nicht mehr gewährleistet. Zwar sind die Beratungen beider Gremien von Gesetzes wegen geheim und ihre Mitglieder jeweils zur Geheimhaltung verpflichtet (vgl. $\S 10$ PKGrG einerseits und $\S 15$ BNG-neu andererseits). Während das Konzept der Rechtskontrolle jedoch gerade auf Effektuierung durch Entpolitisierung setzt, ${ }^{278}$ ist bei der parlamentarischen Kontrolle, die der politischen Logik eines Dualismus

270 Dabei wird u.a. bemängelt, dass der Rekrutierungskreis nicht auch Mitglieder des staatsanwaltschaftlichen Dienstes umfasst. Richterinnen und Richter am Bundesverwaltungsgericht wurden nach einhelliger Kritik im Rahmen der Sachverständigenanhörung nachträglich aufgenommen, vgl. Gärditz (Fn. 34), 912; Graulich (Fn. 12), 128.

271 Vgl. das Gesetz zur weiteren Fortentwicklung der parlamentarischen Kontrolle der Nachrichtendienste des Bundes v. 30.11.2016, BGB1. I S. 2746.

272 Näher Meinel, Schriftliche Stellungnahme an den Innenausschuss v. 18.2.2021, Ausschuss-Drs. 19(4)731 B, S. 2 ff.

273 BT-Drs. 19/26103, S. 104 f.

$274 \S \S 23$ Abs. 1 und 4, 23 Abs. 5 und 7, 33 Abs. 2 Satz 4, 37 Abs. 1 und 4 BNDG-neu.

$275 \S \S 22$ Abs. 3, 29 Abs. 8 Satz 2, 36 Abs. 3, 38 Abs. 8 BNDG-neu.

276 Mit entsprechenden Überlegungen Gärditz (Fn. 34), 913.

277 Gärditz (Fn. 34), 913.

278 Vgl. auch Gärditz (Fn. 9), 832. 
von Regierung und Opposition folgt, eine wirksame Geheimhaltung de facto nicht zu garantieren. ${ }^{279}$

\section{Konsolidierung der nachrichtendienstlichen Rechtsgrundlagen}

Die aufgezeigten Ansätze zur Dogmatisierung und Konstitutionalisierung des Rechts der Nachrichtendienste können nicht darüber hinwegtäuschen, dass diesem Recht nach wie vor eine grundlegende Ordnungsidee fehlt, ${ }^{280}$ die sich vor die Klammer ziehen ließe und eine systematisierende Erfassung des Nachrichtendienstrechts ermöglichen würde. Die Rechtsprechung des Bundesverfassungsgerichts und die daran anschließende BNDG-Reform haben zwar ein Gerüst geschaffen, das zukünftig als Matrix für eine Gesamtreform und Bereinigung des Nachrichtendienstrechts dienen kann. ${ }^{281}$ Den maßgeblichen Strukturmangel des Rechts der Nachrichtendienste haben sie gleichwohl nicht beheben können: Es handelt sich um eine zersplitterte, von dogmatischen Brüchen und systemfremden Anleihen gekennzeichnete Rechtsmaterie, ${ }^{282}$ die sich um das BVerfSchG als Stammgesetz ${ }^{283}$ und Leitregime ${ }^{284}$ des Rechts der Nachrichtendienste gruppiert, dabei jedoch jede Kohärenz vermissen lässt.

Im Bereich des Sicherheitsrechts gibt es kein anderes Teilgebiet, in welchem die einschlägigen Rechtsnormen in ähnlicher Weise über zahlreiche Gesetze, untergesetzliche Verordnungen und interne Verwaltungsvorschriften verteilt sind. ${ }^{285}$ Man spricht von einem „Trümmerhaufen“, ${ }^{286}$ der „dringend einer verfassungsrechtlich angeleiteten Reform“ bedürfe. ${ }^{287}$ Hatten sich die Rechtsgrundlagen der nachrichtendienstlichen Arbeit bereits in der Vergangenheit zu einer hochkomplexen Rechtsmaterie verdichtet, werden die Regelungszusammenhänge zunehmend unübersichtlich. ${ }^{288}$ Zahlreiche und bisweilen unstimmige Querverweise zwischen den Gesetzen erschweren das Verständnis der Regelungsgehalte zusätzlich. ${ }^{289}$ Es mangelt an einer Synchronisierung verbundener Regelungen; ein klarer Rechtsrahmen für die Tätigkeit der Nach-

279 Meinel (Fn. 272), Ausschuss-Drs. 19(4)731 B, S. 4. Vgl. insoweit auch BVerfGE 154, 152, Rn. 298, mit dem relativ unverblümten Hinweis, „,dass Geheimhaltung im parlamentarisch-politischen Umfeld faktischen Grenzen unterliegt".

280 Siehe oben bei Fn. 35.

281 Gärditz (Fn. 34), 913.

282 Löffelmann (Fn. 38), S. 44.

283 Gazeas, Öffentliche Anhörung des Innenausschusses v. 2.11.2020, Protokoll-Nr. 19/109, S. 9.

284 Bäcker (Fn. 117), S. 141; vgl. auch ders. (Fn. 129), Ausschuss-Drs. 19(4)627 B, S. 5: „Leitordnung“.

285 Löffelmann, Novellierung des Bayerischen Verfassungsschutzgesetzes, BayVBl. 2017, 253 (254).

286 Gazeas (Fn. 283), S. 9.

287 Bäcker, Öffentliche Anhörung des Innenausschusses v. 2.11.2020, Protokoll-Nr. 19/109, S. 7.

288 Dietrich (Fn. 3), Kap. III $§ 3$ Rn. 1.

289 Löffelmann (Fn. 285), 254: ,grammatikalisch verschachtelt, sprachlich ungenau und inhaltlich überladen“. 
richtendienste ist weiterhin nicht $\mathrm{zu}$ erkennen. ${ }^{290}$ Die Folge sind Interpretationsprobleme, Anwendungsunfreundlichkeit und Regelungswidersprüche. ${ }^{291}$

\section{Angleichung unterschiedlicher Tatbestandsfassungen}

Erhebliche verfassungsrechtliche Defizite und legistische Widersprüche zeigen sich bereits bei einem Blick auf die Überwachungsermächtigungen innerhalb des BVerfSchG als nachrichtendienstlichem Stammgesetz. Vereinzelt sind diese überzogen restriktiv, überwiegend aber deutlich zu weit gefasst, sodass sie in erheblichem Ausmaß die verfassungsrechtlichen Anforderungen hinsichtlich Eingriffsschwellen und verfahrensrechtlicher Sicherungen verfehlen. ${ }^{292}$ Darüber hinaus weisen sie divergierende Tatbestandsfassungen für verschiedene individualgerichtete Überwachungsmaßnahmen auf, ohne dass sich diese Unterschiede durch Sachgründe (insbesondere eine unterschiedliche Eingriffsintensität) rechtfertigen ließen. So leuchtet zum Beispiel nicht ein, warum die Erhebung einzelner Kontobewegungen einer Person nur unter den restriktiven Voraussetzungen des $\S 8$ a Abs. 3 Satz 1 Nr. 1, 2 BVerfSchG (Förderung schwerwiegender Gefahren) zulässig sein soll, während eine längerfristige Observation dieser Person unter Einsatz technischer Mittel zur Bild- und Tonaufzeichnung durch $\S 9$ Abs. 1 Satz 1 Nr. 1 BVerfSchG annähernd voraussetzungslos und ohne qualifizierte Anforderungen an den Rechtsgüterschutz zugelassen wird. ${ }^{293}$

Eine normative Systematisierung und Harmonisierung der divergierenden Überwachungsermächtigungen setzt eine Evaluierung ihrer Eingriffsintensität voraus. ${ }^{294} \mathrm{Im}$ Anschluss hieran können anhand der Regelungsparameter jeweils Eingriffsschwelle, Rechtsgüterschutz und betroffene aufgabenbezogene Regelungsmuster für Überwachungsmaßnahmen unterschiedlicher Eingriffsintensität entwickelt werden. Für Maßnahmen, die vergleichbare Erkenntnisziele verfolgen und eine vergleichbare Eingriffsintensität aufweisen, sind im Sinne verfassungsrechtlicher Folgerichtigkeit und systematischer Klarheit möglichst dieselben Eingriffstatbestände zu verwenden. ${ }^{295}$

\section{Auflösung mehrgliedriger Verweisungsketten}

Das Problem divergierender und inkohärenter Tatbestandsfassungen wird durch die für das Nachrichtendienstrecht typische Verschachtelungs- und Ergänzungsgesetzgebung noch verschärft. ${ }^{296}$ Diese zeichnet sich dadurch aus, dass vor allem das BNDG

290 Dietrich (Fn. 35), Ausschuss-Drs. 19(4)731 G, S. 23 f.

291 Zusammenfassend Dietrich (Fn. 3), Kap. III § 3 Rn. 71. Beispiele hierfür nennt ders., Ansätze zur Reform des Rechts der Nachrichtendienste, Jahrbuch Öffentliche Sicherheit 2018/2019, $107 \mathrm{ff}$.

292 Bäcker (Fn. 117), S. 149; ders. (Fn. 129), Ausschuss-Drs. 19(4)627 B, S. 3, 5.

293 Vgl. insoweit schon Fn. 132.

294 Hierzu Kugelmann, Die Evaluierung von Polizei- und Sicherheitsgesetzen, in: Gusy (Hrsg.), Evaluation von Sicherheitsgesetzen, 2015, S. 153 ff.; Wolff/Mundil, Die Evaluation von Sicherheitsgesetzen, Jahrbuch Öffentliche Sicherheit 2012/2013, S. $331 \mathrm{ff}$.

295 Bäcker (Fn. 129), Ausschuss-Drs. 19(4)627 B, S. 13.

296 Dietrich (Fn. 35), Ausschuss-Drs. 19(4)731 G, S. 24; ders. (Fn. 99), 182. 
nicht selbst eine tatbestandsmäßige Beschreibung der nachrichtendienstlichen Mittel, ihrer Voraussetzungen und Grenzen vornimmt, sondern in weitem Umfang auf das BVerfSchG verweist. Diese Verweisungstechnik hat ein Ausmaß angenommen, das sich auf Rechtssicherheit und Handlungstransparenz negativ auswirkt. Um nur ein Beispiel zu geben: Bei dem Einsatz eines IMSI-Catchers durch den BND ergibt sich die gebotene nachträgliche Benachrichtigung des Betroffenen aus $\S 5$ Satz 2 BNDG i.V.m. § 9 Abs. 4 Satz 7 BVerfSchG i.V.m. § 8 b Abs. 7 Satz 1 BVerfSchG i.V.m. § 12 Abs. 1 Satz 1 G 10. Dass bei derartigen mehrstufigen Verweisungsketten die Anforderungen der Normenklarheit, Transparenz und Akzeptabilität nachrichtendienstlicher Befugnisse auf der Strecke bleiben, liegt auf der Hand.

Nicht zuletzt das BNDG war in der Vergangenheit Ausdruck eines legislativen Minimalismus, der sich in limitierten Aufgaben- und Befugnisklärungen genauso widerspiegelte wie in extensiven Verweisungen auf das BVerfSchG. Dies geschah auch mit der Intention, die Betroffenen nachrichtendienstlicher Überwachungsmaßnahmen nicht in die Lage zu versetzen, sich auf diese Maßnahmen einstellen zu können. ${ }^{297}$ Demgegenüber setzt der Grundsatz der Normenklarheit einer legislatorischen Verschleierungstaktik sowie der Verwendung gesetzlicher Verweisungsketten von Verfassungs wegen Grenzen. An einer normenklaren Rechtsgrundlage fehlt es zwar nicht schon deshalb, weil in einer Norm auf eine andere Norm verwiesen wird. Doch müssen Verweisungen begrenzt bleiben, dürfen nicht durch die Inbezugnahme von Normen, die andersartige Spannungslagen bewältigen, ihre Klarheit verlieren und in der Praxis nicht zu übermäßigen Schwierigkeiten bei der Anwendung führen. Insofern hat das Bundesverfassungsgericht im BNDG-Urteil betont, dass unübersichtliche „Verweisungskaskaden“ mit den grundrechtlichen Anforderungen an die Normenklarheit nicht vereinbar sind. ${ }^{298}$ Verfassungsrechtlichen Zweifeln begegnete vor diesem Hintergrund etwa die mehrgliedrige Verweisungskette in $\S 24$ Abs. 3 BNDG i.V.m. § 20 Abs. 1 Satz 1 und 2 BVerfSchG, die zu einer Übermittlung von Informationen im Kontext von Staatsschutzdelikten an Polizeien und Staatsanwaltschaften ermächtigt. 299 Die mehrgliedrigen Verweisungsketten zwischen BNDG, MADG und BVerfSchG sind daher zugunsten eigenständiger Rechtsgrundlagen für jede einzelne Behörde aufzulösen. ${ }^{300}$ Dabei kann auch der spezifischen Aufgabe des jeweiligen Dienstes besser Rechnung getragen werden.

\section{Beendigung zweispuriger Eingriffsermächtigungen}

Darüber hinaus sind die Regelungen des Artikel 10-Gesetzes - einschließlich seiner besonderen institutionellen Arrangements (Kontrolle durch die G 10-Kommission) ${ }^{301}$ - in die jeweiligen Fachgesetze zu integrieren. ${ }^{302}$ Im Recht der Nachrichten-

297 Gusy (Fn. 21), BNDG, Vorb. Rn. 10.

298 BVerfGE 154, 152, Rn. 215.

299 BVerfGE 154, 152, Rn. 318.

300 Bäcker (Fn. 117), S. 149; Dietrich (Fn. 35), Ausschuss-Drs. 19(4)731 G, S. 24.

301 Dazu Bantlin (Fn. 248), S. 104 ff. et passim; Huber, Kontrolle der Nachrichtendienste des Bundes, GSZ 2017, $12 \mathrm{ff}$.

302 Bäcker (Fn. 117), S. 149. 
dienste fehlt es bis heute an einem nachvollziehbaren systematischen Regelungsansatz, der Überwachungsmaßnahmen nach ihren Erkenntniszielen und ihrer Eingriffsintensität ordnet und differenzierend reguliert. Nachdem das BNDG-Urteil die Auslandsgeltung des Telekommunikationsgrundrechts aus Art. 10 Abs. 1 GG klargestellt hat, ${ }^{303}$ sind namentlich die komplementären strategischen wie individuellen Eingriffsermächtigungen im BNDG einerseits und dem Artikel 10-Gesetz andererseits (vgl. $\S \S 3-4$ a, 5-8 G 10) nicht mehr erklärbar. Diese Zweispurigkeit der Befugnisnormen wurde ursprünglich mit der mangelnden Auslandsgeltung des Art. 10 Abs. 1 GG und dem insofern begrenzten Anwendungsbereich des G 10 begründet. ${ }^{304}$ Dies kam in $\S 6$ Abs. 4 BNDG a.F. zum Ausdruck, wonach eine Erhebung von Daten aus Telekommunikationsverkehren von deutschen Staatsangehörigen, von inländischen juristischen Personen oder von sich im Bundesgebiet aufhaltenden Personen auf der Grundlage des BNDG unzulässig und nur nach Maßgabe des G 10 gerechtfertigt war. ${ }^{305}$ Spiegelbildlich dazu beschränkt $\S 5$ Abs. 2 Satz 3 G 10 den Anwendungsbereich des Artikel 10-Gesetzes im Rahmen der strategischen Überwachung nach wie vor auf Sachverhalte mit Inlandsbezug. ${ }^{306}$

Obschon diese Zweispurigkeit mit dem BNDG-Urteil hinfällig geworden ist, wird sie von den jüngsten Novellen des Nachrichtendienstrechts tradiert (vgl. $\S \S 34 \mathrm{ff}$. BNDG-neu einerseits und $\S 11$ Abs. 1 a und 1 b G 10 andererseits). ${ }^{307}$ Auch nach der Neuregelung des BNDG finden die Ermächtigungen zur strategischen und individualbezogenen Infiltration informationstechnischer Systeme auf Inlandssachverhalte keine Anwendung. ${ }^{308}$ Im Rahmen einer Gesamtreform des Rechts der Nachrichtendienste sollte diese „eher zufällige“ und ,,anderen Fachgesetzen des Sicherheitsrechts fremde $^{\text {"309 }}$ Aufteilung überwunden und in ein integratives BNDG überführt werden. Das G 10 ist ein Kind der Notstandsverfassung und diente der Ablösung alliierter Vorbehaltsrechte; ${ }^{310}$ inzwischen hat es jedoch seinen normativen Selbststand verloren. Bestrebungen zur Aufhebung des Artikel 10-Gesetzes blieben in der Vergangenheit in-

303 Siehe oben B. I.

304 Differenzierte Darstellung der Überwachungs- und Einsatzkonstellationen bei Marxsen (Fn. 41), $220 \mathrm{ff}$.

305 Vgl. BT-Drs. 18/9041, S. 24: „Die Erhebung von Inhalts- und Verkehrsdaten von deutschen Staatsangehörigen, inländischen juristischen Personen oder sich im Bundesgebiet aufhaltenden Personen richtet sich nach dem Artikel 10-Gesetz".

306 Obschon sie im BVerfG-Urteil über die Ausland-Ausland-Fernmeldeaufklärung nicht explizit beanstandet wurde, ist die Norm als verfassungswidrig anzusehen. $\S 5$ Abs. 2 Satz 3 G 10 ermöglicht einen unverhältnismäßigen Eingriff in das auch für Ausländer geltende Fernmeldegeheimnis und begründet insoweit eine sachwidrige Ungleichbehandlung, vgl. Durner, in: Maunz/Dürig, GG, 94. Erg.-Lfg. 2021, Art. 10 Rn. 242, m.w.N.; Huber, in: Schenke/Graulich/Ruthig (Hrsg.), Sicherheitsrecht des Bundes, 2. Aufl. 2019, G 10, § 5 Rn. $41 \mathrm{ff}$;; ders., Die strategische Rasterfahndung des Bundesnachrichtendienstes, NJW 2013, 2572 (2574); Marxsen (Fn. 41), 227; zur Vorgängerregelung des § 3 Abs. 2 Satz 3 G 10 a.F. schon Müller-Terpitz, Die „strategische Kontrolle“ des internationalen Telekommunikationsverkehrs durch den Bundesnachrichtendienst, JURA 2000, 296 (302).

307 Dazu oben IV.

308 Vgl. $\S \S 19$ Abs. 7 Satz 1, 34 Abs. 6 Satz 3 BNDG-neu.

309 Gärditz (Fn. 34), 910.

310 Gärditz (Fn. 52), S. 154. 
des erfolglos. ${ }^{311}$ Wie in anderen Bereichen des Sicherheitsrechts sollten die Regelungen nach Eingriffstypik, Behördenstruktur, korrespondierender Kompetenzgrundlage und Aufgabenprofil geordnet werden, nicht nach der Systematik der - tatsächlich oder vermeintlich - betroffenen Grundrechte. ${ }^{312}$

\section{Entflechtung sicherheitsbehördlicher Doppelzuständigkeiten}

Im Rahmen einer Konsolidierung der nachrichtendienstlichen Rechtsgrundlagen sollten schließlich funktionale Überschneidungen und behördliche Doppelzuständigkeiten in den Blick genommen werden. Die weit in das Vorfeld ausgreifende Aufklärung einer Gefahr und Gewinnung von Gefährdern und Verdächtigen muss - so jedenfalls das verfassungsgerichtlich geprägte Leitbild ${ }^{313}$ - organisatorisch, befugnisrechtlich und informationell getrennt von der Polizei über die Nachrichtendienste und den Verfassungsschutz erfolgen. Letztere können ihre Erkenntnisse sodann unter näher bestimmten Voraussetzungen an die Polizeibehörden und Staatsanwaltschaften übermitteln. Im Gefolge der aufgezeigten „Vernachrichtendienstlichung der Polizei“ sowie der „Verpolizeilichung der Nachrichtendienste“ ${ }^{\text {314 }}$ rücken beide Rechtsregime allerdings immer weiter aufeinander zu und überschneiden sich bereits in zahlreichen Anwendungsbereichen. Auch institutionell sind Polizei und nachrichtendienstlicher Verfassungsschutz über gemeinsam betriebene Informationssysteme miteinander verbunden. ${ }^{315}$ Mit der Übertragung der präventivpolizeilichen Maßgaben aus dem BKAGUrteil auf das Recht der Nachrichtendienste und der Bestätigung einer verfassungsrechtlichen Konvergenz zwischen beiden Bereichen hat das Bundesverfassungsgericht diese nun im Gefüge des Sicherheitsverfassungsrechts verklammert. Dem Trennungsgebot kommt dabei - ungeachtet seiner verfassungsrechtlichen Verankerung - mehr und mehr der Charakter einer wenig trennscharfen „Tendenz“ als einer strikten organisations- oder informationsrechtlichen Handlungsanweisung zu. ${ }^{316}$

Die Aufgabenverteilung zwischen Polizei und Nachrichtendiensten in der Praxis bleibt hiervon nicht unberührt. Dies gilt namentlich im Bereich der Terrorismusbe-

311 Vgl. den Entwurf eines Gesetzes zur Aufhebung des Artikel 10-Gesetzes und weiterer Gesetze mit Befugnis für die Nachrichtendienste des Bundes zu Beschränkungen von Artikel 10 des Grundgesetzes (G 10-Aufhebungsgesetz - G 10-AufhG) der Fraktion DIE LINKE v. 2.7.2015, BT-Drs. 18/5453.

312 Gärditz (Fn. 34), 906; Graulich (Fn. 12), 127.

313 Siehe oben Fn. 155.

314 Siehe oben bei Fn. 102.

315 Näher Stubenrauch, Gemeinsame Verbunddateien von Polizei und Nachrichtendiensten, 2009; Fremuth, Wächst zusammen, was zusammengehört? AöR 139 (2014), 32 ff.; vgl. auch Gusy (Fn. 155), 249; ders., Parlamentarische Kontrolle der Nachrichtendienste im demokratischen Rechtsstaat, ZRP 2008, 36 (39).

316 Thiel (Fn. 92), S. 373 ff.; Volkmann, Verbund oder Trennung, JURA 2014, 820 (829), mit dem Hinweis, die leitbildartige Abschichtung der wechselseitigen Aufgabenbereiche in der Entscheidung zur Antiterrordatei (vgl. BVerfGE 133, 277, Rn. 115 ff.) wirke insoweit „stark idealisiert“ und habe ,in der Realität schon seit längerem kaum noch eine Stütze“ gefunden. 
kämpfung und des „Gefährdermanagements“.317 So hat der Anschlag auf den Breitscheidplatz in Berlin im Dezember 2016 (,Fall Amri“ ${ }^{318}$ deutlich gemacht, dass eine klare Abgrenzung bisweilen schwierig ist, da es insbesondere im Bereich der Staatsschutzdelikte Straftaten gibt, die weit in die Vorbereitungsphase hineinreichen, und somit eine Überschneidung der Zuständigkeitsbereiche nicht immer auszuschließen ist. De lege lata ist durchaus eine parallele Aufgabenwahrnehmung beider Behörden mit unterschiedlichen sachlichen Zuständigkeiten zulässig. Im Ergebnis dürften diese Überschneidungen jedoch einerseits nicht dazu führen, „dass es zu unabgestimmten Doppelbearbeitungen kommt, andererseits nicht dazu, dass ein Tätigwerden im Vertrauen darauf unterbleibt, dass eine Bearbeitung durch die jeweils andere Stelle erfolgt". ${ }^{319}$ Wenn keine klaren und verbindlichen Zuständigkeitszuweisungen getroffen werden, welche Behörde für welche Maßnahme die Verantwortung trägt, besteht die Gefahr, dass Zuständigkeitsüberschneidungen - nach dem jedem Fußballer bekannten Motto: „Nimm Du ihn, ich hab ihn sicher“ - letztlich zu Lücken in der Überwachung oder zu Informationsdefiziten führen. Abhilfe soll durch eine verbesserte verbindliche Nutzung der bestehenden Datensysteme auch für die Informationssteuerung sowie durch eine Förderung des direkten Informationsaustausches geschaffen werden. ${ }^{320}$

\section{Fazit und Ausblick}

Das Recht der Nachrichtendienste befindet sich im Umbruch. Auf der einen Seite hat es in der jüngeren Vergangenheit eine Verrechtlichung, Vergesetzlichung und verfassungsrechtliche Verankerung in durchaus beachtlichem Umfang erfahren. Auf der anderen Seite stehen die seit langem überfällige Gesamtreform und Bereinigung dieser Rechtsmaterie noch immer aus. Die als Reaktion auf die jüngere Rechtsprechung des Bundesverfassungsgerichts verabschiedete BNDG-Reform hat zwar die gravierendsten verfassungsrechtlichen Missstände behoben. Sie vermochte jedoch die strukturellen, systematischen wie methodischen Defizite im Nachrichtendienstrecht nicht zu beseitigen. Einem legistischen Trümmerhaufen kann man mit Flickwerk nicht beikommen. Letztlich müsste man ,im Wesentlichen das geltende Recht wegwerfen und neu machen".321 Entwürfe für eine umfassende Konsolidierung liegen bereits in den Schubladen der Ministerien. Es wird sich zeigen müssen, ob sich die politischen Mehrheiten für ihre Umsetzung finden.

317 Vgl. Binninger, Das Nebeneinander von Bundes- und Landesbehörden in der Inneren Sicherheit, Jahrbuch des Föderalismus, 2018, 88 (98); Kretschmer, Globale Trends und Auswirkungen auf die Polizeiarbeit, in: Lange/Model/Wendekamm (Hrsg.), Zukunft der Polizei, 2019, S. 35 (39).

$318 \mathrm{Zu}$ den hierdurch initiierten Änderungen in der Sicherheitsgesetzgebung Barczak, Verallgemeinerung des Außergewöhnlichen, ZRP 2021, 122 ff., m.w.N.

319 So der Abschlussbericht des 1. Untersuchungsausschusses des Abgeordnetenhauses von Berlin zur Untersuchung des Ermittlungsvorgehens im Zusammenhang mit dem Terroranschlag am Breitscheidplatz am 19.12.2016, Drs. 18/4000 v. 9.8.2021, S. 927.

320 Abgeordnetenhaus von Berlin, Abschlussbericht (Fn. 319), S. 155.

321 Bäcker (Fn. 287), S. 7. 